\title{
Nek2B activates the wnt pathway and promotes triple-negative breast cancer chemothezrapy-resistance by stabilizing $\beta$ - catenin
}

Honghong Shen ${ }^{1+}$, Wenpeng Yan ${ }^{1+}$, Jinyang Yuan ${ }^{2}$, Ziyue Wang ${ }^{1}$ and Chen Wang ${ }^{1 *}$

\begin{abstract}
Background: The chemotherapy-resistance of triple-negative breast cancer (TNBC) remains a major challenge. The Nek2B kinase and $\beta$-catenin serve as crucial regulators of mitotic processes. The aim of this study was to test the correlation between Nek2B and TNBC chemotherapy sensitivity, and to determine the regulation of Nek2B on $\beta$-catenin and wnt/ $\beta$-catenin signal pathway.

Methods: Gene Expression Omnibus(GEO) databases were used to gather gene exprsssion data of TNBC patients who undergoing chemotherapy. The co-expression of Nek2B and $\beta$-catenin in TNBC surgical sections and cells were analysed by immunohistochemistry, Q-RT-PCR, Western-blot and immunofluorescent staining. The impact of the expression of Nek2B and $\beta$-catenin in prognosis was also assessed using the Kaplan-Meier curves. CCK8 assay was used to detect the IC50 value of TNBC cell line. The endogenous binding capacity of Nek2B and $\beta$-catenin and phosphorylation of $\beta$-catenin by Nek2B were detected using co-immunoprecipitation (CO-IP). Chromatin immuneprecipitation (ChIP) analysis and Luciferase Assays were used to evaluate the binding ability of the Nek2B, $\beta$-catenin and TCF4 complex with LEF-1 promoter. Nek2B-siRNA and Nek2B plasmid were injected into nude mice, and tumorigenesis was monitored.
\end{abstract}

Results: We found that overexpression of Nek2B and $\beta$-catenin in TNBC samples, was associated with patients poor prognosis. Patients with positive Nek2B expression were less sensitive to paclitaxel-containing neoadjuvant chemotherapy. Interestingly, in a panel of established TNBC cell line, Nek2B and $\beta$-catenin were highly expressed in cells exhibiting paclitaxel resistance. Our data also suggest that $\beta$-catenin binded to and was phosphorylated by Nek2B, and was in a complex with TCF4. Nek2B mainly regulates the expression of $\beta$-catenin in TNBC nucleus. Nek2B, $\beta$-catenin and TCF4 can be binded with the WRE functional area of LEF-1 promoter. Nek2B can activite wnt signaling pathway and wnt downstream target genes. The tumors treated by Nek2B siRNA associated with paclitaxel were the smallest in nude mouse, and Nek2B can regulate the expression of $\beta$-catenin and wnt downstream target genes in vivo.

Conclusion: Our study suggested that Nek2B can bind to $\beta$-catenin and the co-expression correlated with TNBC patients poor prognosis. It appears that Nek2B and $\beta$-catenin might synergize to promote chemotherapy resistance.

Keywords: Nek2B, $\beta$-Catenin, Wnt signaling pathway, Triple-negative breast cancer, Chemotherapy resistance

\footnotetext{
* Correspondence: chenwangshh@126.com

${ }^{\dagger}$ Honghong Shen and Wenpeng Yan contributed equally to this work.

'Department of pathology, The Second Clinical Medical College, Shanxi

Medical University, 382 Wuyi Road, Taiyuan 030001, People's Republic of

China

Full list of author information is available at the end of the article
}

(c) The Author(s). 2019 Open Access This article is distributed under the terms of the Creative Commons Attribution 4.0 International License (http://creativecommons.org/licenses/by/4.0/), which permits unrestricted use, distribution, and reproduction in any medium, provided you give appropriate credit to the original author(s) and the source, provide a link to the Creative Commons license, and indicate if changes were made. The Creative Commons Public Domain Dedication waiver (http://creativecommons.org/publicdomain/zero/1.0/) applies to the data made available in this article, unless otherwise stated. 


\section{Background}

Approximately $15 \%$ of breast cancers are classified as triple-negative breast cancer (TNBC), lacking expression of the estrogen receptor and the progesterone receptor, and which is characterized by absence or low expression or no amplification on the gene level, of the human epidermal growth factor receptor $2[1,2]$. Treatment of TNBC, which often presents with a more aggressive phenotype, is more difficult due to the paucity of potential target molecules. Therefore, there is a critical need to enhance current systemic treatments and identify new targets for the treatment of TNBC [3].

Because the centrosome cycle is regulated by protein phosphorylation and given the importance of mitotic and centrosomal kinases, they are attractive targets for anti-mitotic anticancer drugs [4]. NIMA-related kinase 2 (Nek2), which has at least three spliced isomers: Nek2A, Nek2B and Nek2C, is such a target. Nek2B is the only Nek2 isomer that runs through the whole process of mitosis [5]. It can regulate centrosome aggregation and separation by regulating the mitotic centrosome separation through reversible phosphorylation of its substrates [6,7]. High levels of Nek2B are linked to a poor disease-free survival (DFS) and overall survival (OS) in TNBC and other cancers [8]. Nek2 depletion affected the kinetochores-microtubule attachment, inducing a spindle checkpoint imbalance and abnormal clustering of kinetochore components, resulting in increased sensitivity of cells to the microtubule targeting anticancer drug paclitaxel [9]. In spite of the increasing evidence of the importance of Nek2B in cancer development, its role in cancer is still far from clear.

The wnt signaling pathway is an important extracellular pathway comprises two different intracellular signaling pathways: the $\beta$-catenin-dependent pathway (known as the canonical Wnt pathway) and the $\beta$-catenin-independent pathway (known as the noncanonical Wnt pathway). Compared with other signaling pathways, the canonical Wnt/ $\beta$-catenin pathway is highly evolutionary conserved and mainly involves $\beta$-catenin [10]. $\beta$-catenin is a well-studied protein with known functions in the nucleus in a complex with the transcriptional coactivator T-cell factor/lymphocyte enhancer factor-1 (TCF/LEF-1) [11]. Similar to Nek2, $\beta$-catenin localizes to centrosomes throughout the cell cycle, and $\beta$-catenin localization to interphase centrosomes is mediated by the linker proteins [12]. $\beta$-catenin was also identified as a substrate for Nek2 kinase in vivo and in vitro [13]. Nek2 activity is regulated during the cell cycle and peaks at the G2/M boundary when $\beta$-catenin localization to centrosomes. The peak of Nek2 activity at the G2/M boundary coincides with a linker-protein independent increase of $\beta$-catenin at centrosomes [14]. However, studies concerning the expression of Nek2B and $\beta$-catenin in human TNBC have not been reported previously.

Our goal in this study is to identify a reliable, clinically useful prognostic gene-expression signature that offers novel clinical opportunities for predicting drug resistance and developing novel treatments in TNBC. We determined the effects of Nek2B-overexpression on drug resistance and explored the binding abilitity of Nek2B and $\beta$-catenin in TNBC cells.

\section{Materials and methods}

Patients and tissue specimens

One hundred and seventy-four TNBC breast cancer samples were obtained from 1114 breast cancer patients at the Second Clinical Medical College, Shanxi Medical University, China, during January 1, 2007 and December 31, 2012. Patients who met the following criteria were eligible for this study: (1) patients with invasive TNBC, (2) patients who have completed follow-up date during the study period.

\section{Immunohistochemistry}

Immunohistochemical analyses were performed on formalin-fixed, paraffin-embedded sections of surgical specimen as described previously [15]. The primary antibody rabbit monoclonal anti-human Nek2B antibody (ab227958, Abcam, Cambridge, MA, USA) at 1:250 dilution or mouse monoclonal anti-human $\beta$-catenin antibody (ab32572, Abcam) at 1:200 dilution was incubated overnight at $4{ }^{\circ} \mathrm{C}$. For scoring Nek2B and $\beta$-catenin expression, the intensity (intensity score: $0=$ negative, $1=$ weak, $2=$ moderate, and $3=$ strong) and percentage of the total cell population (proportion score: $0,0 \% ; 1,<$ $25 \%$; $2,25-49 \%$; $3,50-74 \% ; 4, \geq 75 \%$ ) were evaluated for each case. The expression was regarded as negative (intensity multiply proportion scores $0-1$ ) or positive (intensity multiply proportion scores $\geq 2$ ) using high-powered $(\times 200)$ microscopy.

\section{Cell lines and culture conditions}

Human TNBC cell lines Hs578T, BT20, MDA-MB-231 and MDA-MB-468 were chosen. Cells were cultured in DMEM medium (Gibco) or RPMI 1640(Gibco), 10\% fetal bovine serum (FBS)(Gibco) and 1\% penicillin/ streptomycin (Life Technologies Inc), under a humidified atmosphere without $\mathrm{CO}_{2}$ at $37^{\circ} \mathrm{C}$.

\section{CCK8 assay}

Cell proliferation viability was measured with a Cell Counting Kit-8 (CCK8, Beyotime) following the manufacturer's instructions. The absorbance was measured at $450 \mathrm{~nm}$ on a microplate reader. The OD value was checked every $24 \mathrm{~h}$. Each experiment was performed in triplicate. 
Reverse transcription quantitative real-time polymerase chain reaction (Q-RT-PCR)

Total RNA was isolated from cells, and qPCR was performed as described previously [15]. Target gene expression values were normalized to Actin. The primers used for $\mathrm{qPCR}$ are as follows:

Actin-Fwd:5' -AGCGAGCATCCCCCAAAGTT-3'

Actin-Rev:5'-GGGCACGAAGGCTCATCATT-3'.

Nek2B-Fwd:5' -CTAGCTAGCTAGCCGTCACGGG

TCGAG-3'.
Nek2B-Rev:5' -CGGGATCCTTAGAATTTGCTCCA TTCATTCC-3'.

B-catenin-Fwd:5' -ACTTGCCACACGTGCAATTC-3' . B-catenin-Rev:5' -ATGGTGCGTACAATGGCAGA-3'.

\section{Western-blot}

The total protein was extracted from each sample using RIPA buffer containing protease inhibitors. Total cell lysates containing $10 \mu \mathrm{g}$ of protein were electrophoresed on a SDS-PAGE and then transferred to PVDF membranes (Millipore, MA, USA). The sample was blocked with 5\%

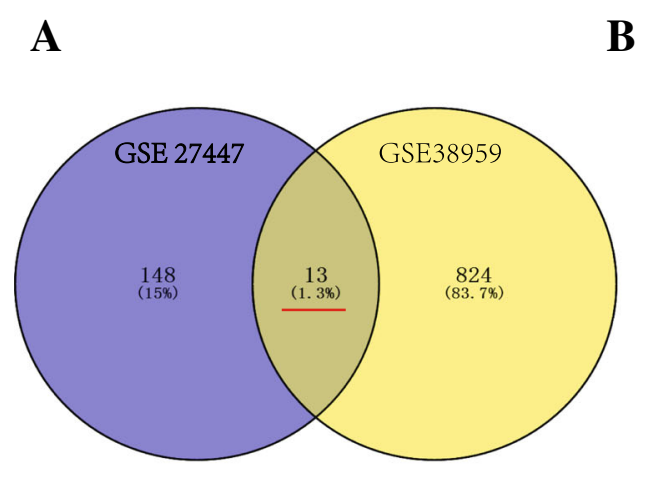

B

GSE27447

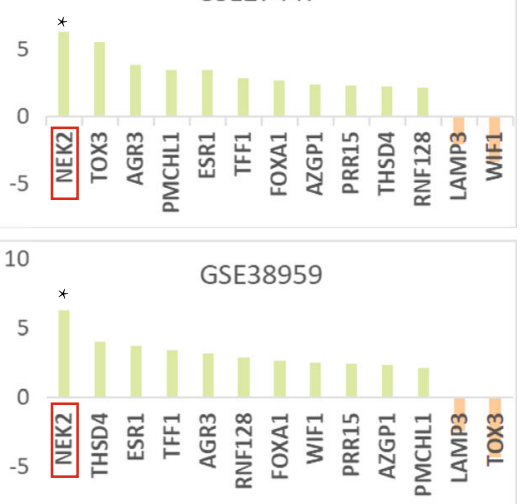

C

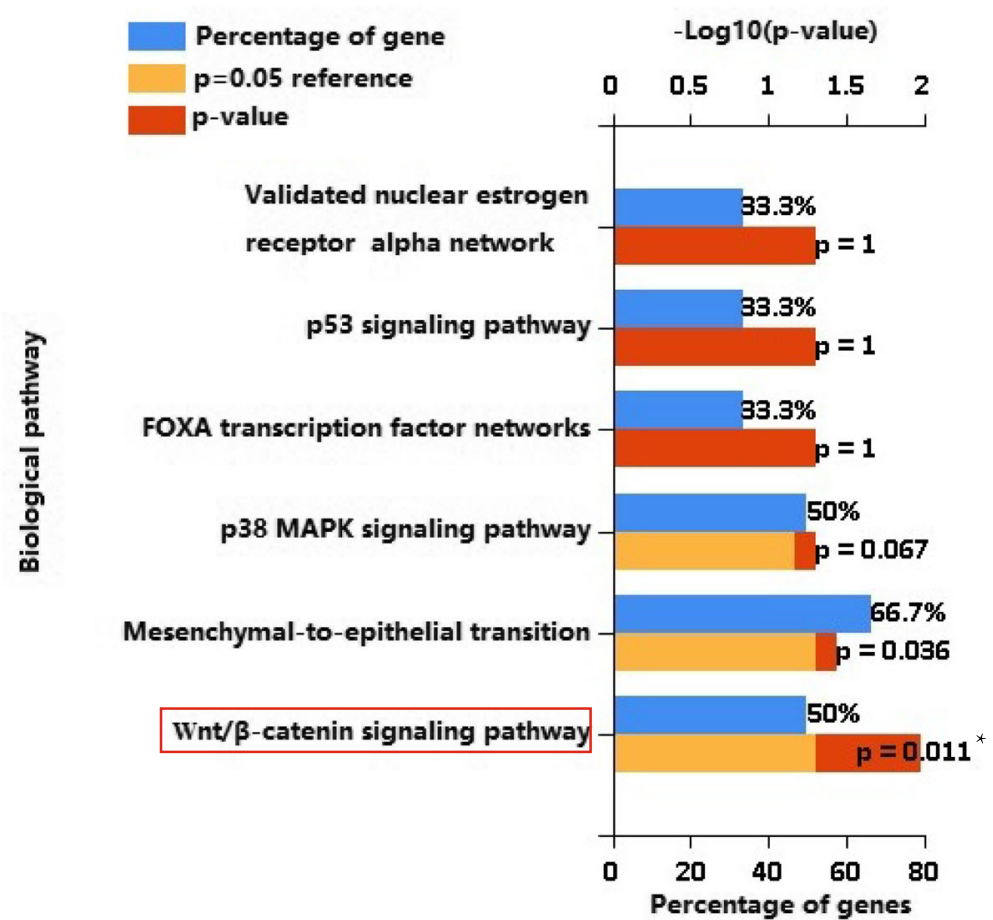

Fig. 1 (a) Venn diagram of the overlaps between GSE27447 DEGs and GSE38959. DEGs. There were 13 common differential genes between the two circles; (b) Relative expression of 13 common differential genes in GSE27447 DEGs and GSE38959 DEGs; (c) Enrichment analysis of the KEGG pathway. ${ }^{*} P<0.05 ;{ }^{*} P<0.01$ 


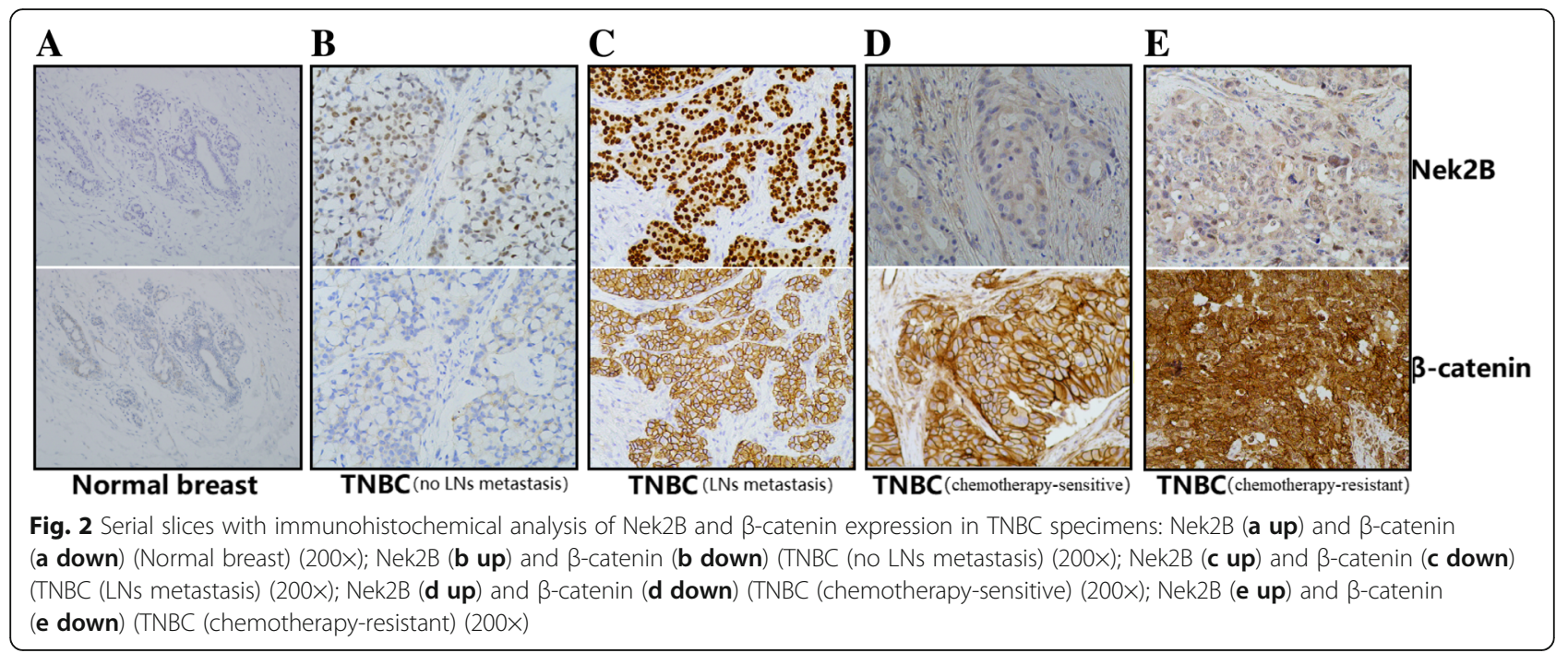

fat-free milk for $1 \mathrm{~h}$, and incubated with primary antibodies for $1 \mathrm{~h}$ and with secondary antibodies for $1 \mathrm{~h}$. The primary antibodies, including anti-Nek2B (ab227958; Abcam) at 1:2000 and anti- $\beta$-catenin (ab32572; Abcam) at 1:5000 were used in the present study. The blots were visualized using ECL assay.

\section{Immunofluorescence}

Immunofluorescence was performed as described previously [15]. The two set mixed primary antibody including anti-rabbit monoclonal Nek2B antibody (200ul, $1: 500)$ and anti-mouse monoclonal $\beta$-catenin antibody (200ul, 1:250). Cells were mounted with DAPI away from light. The signal of Alexa Fluor 488 was visualized as green (Nek2B) and Alexa Fluor 594 as red ( $\beta$-catenin).

\section{Nuclear and cytoplasmic extraction}

Nuclear and cytoplasmic fractions were isolated using NE-PER Nuclear and Cytoplasmic Extraction Reagents (Thermo Fisher Scientific, Waltham, MA) according to the instructions provided by the manufacturer.

\section{Immune protein coprecipitation (CO-IP)}

Cell lysates were incubated for $4 \mathrm{~h}$ at $4{ }^{\circ} \mathrm{C}$ with the indicated antibodies and protein $\mathrm{A} / \mathrm{G}$ beads (Thermo Fisher Scientific, Waltham, MA) or with anti-FLAG (Sigma-Aldrich, St. Louis, MO) or anti-HA (Sigma-Aldrich, St. Louis, MO) agarose gels for FLAG-OR HA-tagged protein pull-down. After incubation, beads were washed with low salt lysis buffer, boiled with $4 \times$ SDS loading buffer. IB analysis was developed using the Western HRP Chemiluminescence Substrates (Millipore, Burlington, MA) .
Table 1 The expression of Nek2B and $\beta$-catenin with clinicopathological features in TNBC patients

\begin{tabular}{|c|c|c|c|c|c|c|c|c|c|}
\hline \multirow[t]{3}{*}{ Factors } & & \multicolumn{4}{|c|}{ Nek2B P } & \multicolumn{4}{|c|}{$\beta$-catenin $P$} \\
\hline & & \multicolumn{2}{|c|}{ Positive } & \multicolumn{2}{|c|}{ negative } & \multicolumn{2}{|c|}{ Positive } & \multicolumn{2}{|c|}{ negative } \\
\hline & & $\mathrm{N}$ & $\%$ & $\mathrm{~N}$ & $\%$ & $\mathrm{~N}$ & $\%$ & $\mathrm{~N}$ & $\%$ \\
\hline$\overline{\text { All }}$ & 174 & 116 & 66.7 & 58 & 33.3 & 150 & 86.2 & 24 & 13.8 \\
\hline Age & & & & & 0.824 & & & & 0.197 \\
\hline$\leq 50$ & 110 & 74 & 67.3 & 36 & 32.7 & 92 & 83.6 & 18 & 16.4 \\
\hline$>50$ & 64 & 42 & 65.6 & 22 & 34.4 & 58 & 90.6 & 6 & 9.4 \\
\hline Tumor size $(\mathrm{cm})$ & & & & & $0.033^{\mathrm{a}}$ & & & & 0.975 \\
\hline$\leq 2$ & 26 & 14 & 53.8 & 12 & 46.2 & 24 & 92.3 & 2 & 7.7 \\
\hline$>2 ; \leq 5$ & 96 & 72 & 75.0 & 24 & 25.0 & 82 & 85.4 & 14 & 14.6 \\
\hline$>5$ & 52 & 30 & 57.7 & 22 & 42.3 & 44 & 84.6 & 8 & 15.4 \\
\hline Tumor grade & & & & & $<0.0001^{\mathrm{a}}$ & & & & 0.593 \\
\hline G1-G2 & 64 & 24 & 37.5 & 40 & 62.5 & 54 & 84.4 & 10 & 15.6 \\
\hline G3 & 110 & 92 & 83.6 & 18 & 16.4 & 96 & 87.3 & 14 & 12.7 \\
\hline LNs metastasis & & & & & $0.003^{\mathrm{a}}$ & & & & 0.191 \\
\hline No & 80 & 44 & 55.0 & 36 & 45.0 & 66 & 82.5 & 14 & 17.5 \\
\hline Yes & 94 & 72 & 76.6 & 22 & 23.4 & 84 & 89.4 & 10 & 10.6 \\
\hline Ki67 & & & & & $<0.0001^{*}$ & & & & $0.003^{\mathrm{a}}$ \\
\hline$<20 \%$ & 82 & 42 & 51.2 & 40 & 48.8 & 64 & 78.0 & 18 & 22.0 \\
\hline$\geq 20 \%$ & 92 & 74 & 80.4 & 18 & 19.6 & 86 & 93.5 & 6 & 6.5 \\
\hline$\beta$-catenin & & & & & $0.001^{\mathrm{a}}$ & & & & \\
\hline Negative & 24 & 8 & 33.3 & 16 & 66.7 & - & & - & \\
\hline Positive & 150 & 108 & 72.0 & 42 & 28.0 & - & & - & \\
\hline Radiotherapy & & & & & 0.782 & & & & 0.814 \\
\hline No & 142 & 94 & 66.2 & 48 & 33.8 & 122 & 85.9 & 20 & 14.1 \\
\hline Yes & 32 & 22 & 68.8 & 10 & 31.3 & 28 & 87.5 & 4 & 12.5 \\
\hline Chemotherapy & & & & & 0.646 & & & & 0.897 \\
\hline No & 56 & 36 & 64.3 & 20 & 35.7 & 48 & 85.7 & 8 & 14.3 \\
\hline Yes & 118 & 80 & 67.8 & 38 & 32.2 & 102 & 86.4 & 16 & 13.6 \\
\hline
\end{tabular}

LNs Lymph nodes; ${ }^{a}$ Difference was statistically significant 

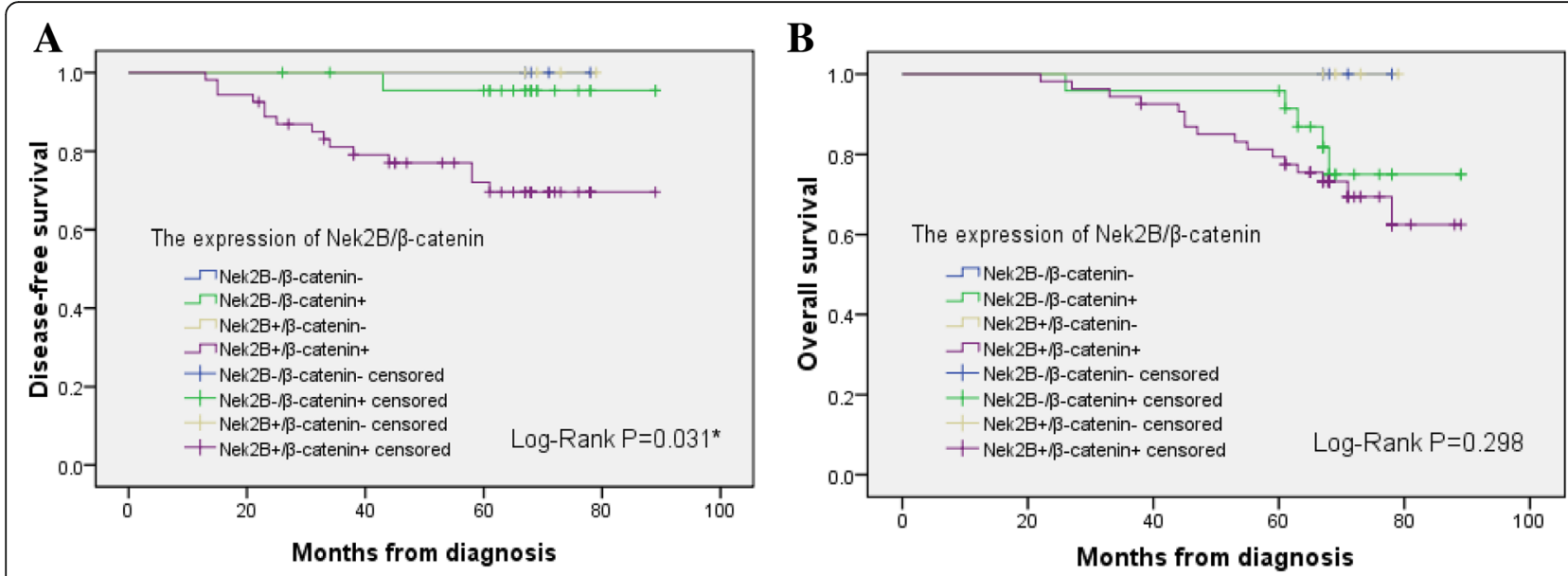

Fig. 3 Kaplan-Meier curves for impact of the expression of Nek2B/ $\beta$-catenin on disease-free survival (a) and overall survival (b). Log-rank $P$ values are shown above

\section{Chromatin immunoprecipitation (ChIP)}

ChIP assay was performed according to instruction (Millipore). ChIP assays were performed using primers spanning binding sites in the LEF-1 promoter. $20 \mu \mathrm{l}$ magnetic AG-beads (Invitrogen) were used for each ChIP. DNA was purified using DNA Purification Buffer plus DNA purification magnetic beads, as recommended (Invitrogen).

\section{Luciferase assays}

TNBC cells were transfected with pGL4-LEF-1-prom-Luc reporters along with plasmids using the Lipofectamie 2000 (Invitrogen, USA) as indicated in the figures. After $48 \mathrm{~h}$ of transfection, cell lysates were subjected to luciferase assays according to the Dual-Luciferase Reporter Assay protocol (Promega, Madison, WI). Each experiment was repeated in triplicates.

\section{Invasion assays}

Transwell migration assays were performed using a transwell membrane ( $8-\mu \mathrm{m}$ pore size, $6.5-\mathrm{mm}$ diameter; Corning Incorporated, Corning, NY, USA) in a 24-well plate according to the manufacturer's instructions. The cells were placed in incubators at $37^{\circ} \mathrm{C}$ for different time periods according to preliminary experiments. The upper surface cells were removed using cotton swabs, those on the lower surface were fixed with $4 \%$ paraformaldehyde in PBS, stained with $0.1 \%$ crystal violet and counted.

\section{In vivo experiments}

Female BALB/c nude mice of 4-6 weeks old and body weight of $20 \pm 2 \mathrm{~g}$ were housed in specific pathogenfree (SPF) conditions. All the rats were administered as described previously [16]. All the rats were sacrificed after 30 days and the masses were resected.

\section{Follow-up study}

The primary endpoints were disease-free survival (DFS) and overall survival (OS). DFS was calculated as time from surgery to locoregional recurrence, distant metastasis, or death. OS was determined as the time from surgery until the date of death or was censored at the date of last follow-up.

\section{Statistical analysis}

The statistical significance between Nek2B and $\beta$-catenin expression and patients' clinicopathological status was tested using chi square $\left(\chi^{2}\right)$ test. The correlation of Nek2B and $\beta$-catenin expression with patient prognosis was determined by Kaplan-Meier method. A two-sided $p$-value of $<0.05$ was considered significant. All in vitro experiments were performed in triplicate. Data are represented as mean \pm S.E. All analyses were performed using SPSS 22.0.

\section{Results}

Nek2 was listed as an TNBC chemotherapy-resistant candidate biomarker by integrated analysis

Related gene data set GSE27447 and GSE38959 of TNBC patients who undergoing chemotherapy was downloaded from GEO database and divided into chemotherapy-sensitive group (no local recurrence) and

Table 2 The expression of Nek2B with chemotherapy sensitivity of TNBC patients

\begin{tabular}{llllll}
\hline & PR & SD & PD & $X^{2}$ & $P$ value \\
\hline Nek2B & & & & 13.388 & $0.003^{\mathrm{a}}$ \\
Negative & $6(50.0 \%)$ & $4(33.3 \%)$ & $2(16.7 \%)$ & & \\
Positive & $8(26.7 \%)$ & $6(20.0 \%)$ & $16(53.3 \%)$ & & \\
\hline
\end{tabular}

$P R$ partial response, $S D$ stable condition, $P D$ disease progression; ${ }^{\text {aD }}$ ifference was statistically significant 
chemotherapy-resistance group (local recurrence). Thirteen differentially expressed genes related to the chemotherapy drug resistance were found using GEO2R analysis tools (Fig. 1a), of which 11 upregulation and 2 downregulation. Nek2 is the most obvious gene of upregulation genes $(P<0.05)$ (Fig. 1b). Gene Ontology (GO) enrichment analysis and Kyoto Encyclopedia of Genes and Genomes (KEGG) pathway enrichment analysis were conducted respectively through DAVID database. GO enrichment analysis showed that differentially expressed genes were significantly enriched in cell cycle, stem cell differentiation, cell apoptosis and other biological processes. The enrichment analysis of KEGG pathway showed that Nek2 was involved in wnt/ $\beta$-catenin signal pathway (Fig. 1c).

\section{The expression of Nek2B and $\beta$-catenin by} immunohistochemistry

We included in the analysis 174 women with TNBC at the Second Clinical Medical College, Shanxi Medical University, China, during 2007-2012. The Nek2B protein is expressed in cytoplasm and nuclear (Fig. 2 up). The $\beta$-catenin protein is mainly expressed in membrane (Fig. 2 down). Low or no expression of Nek2B and $\beta$-catenin in normal breast tissue (Fig. 2a); The expression intensity of Nek2B and $\beta$-catenin in TNBC tissues with lymph nodes (LNs) metastasis (Fig. 2c) was higher than that without LNs metastasis (Fig. 2b), while it was higher in chemotherapy-resistant tissues (Fig. 2e) than in chemotherapy-sensitive tissues (Fig. 2d).

\section{The expression of Nek2B and $\beta$-catenin with clinical- pathological and prognosis}

As shown in Table 1, the age of the patients ranged from 36 to 80 years with a mean age and median age of 53.0 years and 51.5 years, respectively. In specimens from patients with TNBC, Nek2B was expressed in 116 cases (66.7\%), $\beta$-catenin was expressed in 150 cases (86.2\%). The number of patients with positive Nek2B expression was significantly higher in the high tumor grade(G3) group $(P<0.0001)$, LNs metastasis group $(P=0.003)$, and high Ki67 index group $(P<0.0001)$. Nek2B tended to be higher in $\beta$-catenin positive cases (72.0\%). The number of patients with positive $\beta$-catenin expression was significantly higher in the high Ki67 index group $(P=0.003)$. As shown in Fig. 3, the Kaplan-Meier curves showed that patients with $\mathrm{Nek} 2 \mathrm{~B}+/ \beta$-catenin + expression have lower DFS rates compared with other groups $(P=0.031)$.

\section{The expression of Nek2B with chemotherapy resistance}

To explore the relationship between Nek2B expression and paclitaxel resistance, we selected 43 patients diagnosed with TNBC by needle core biopsy, all of whom

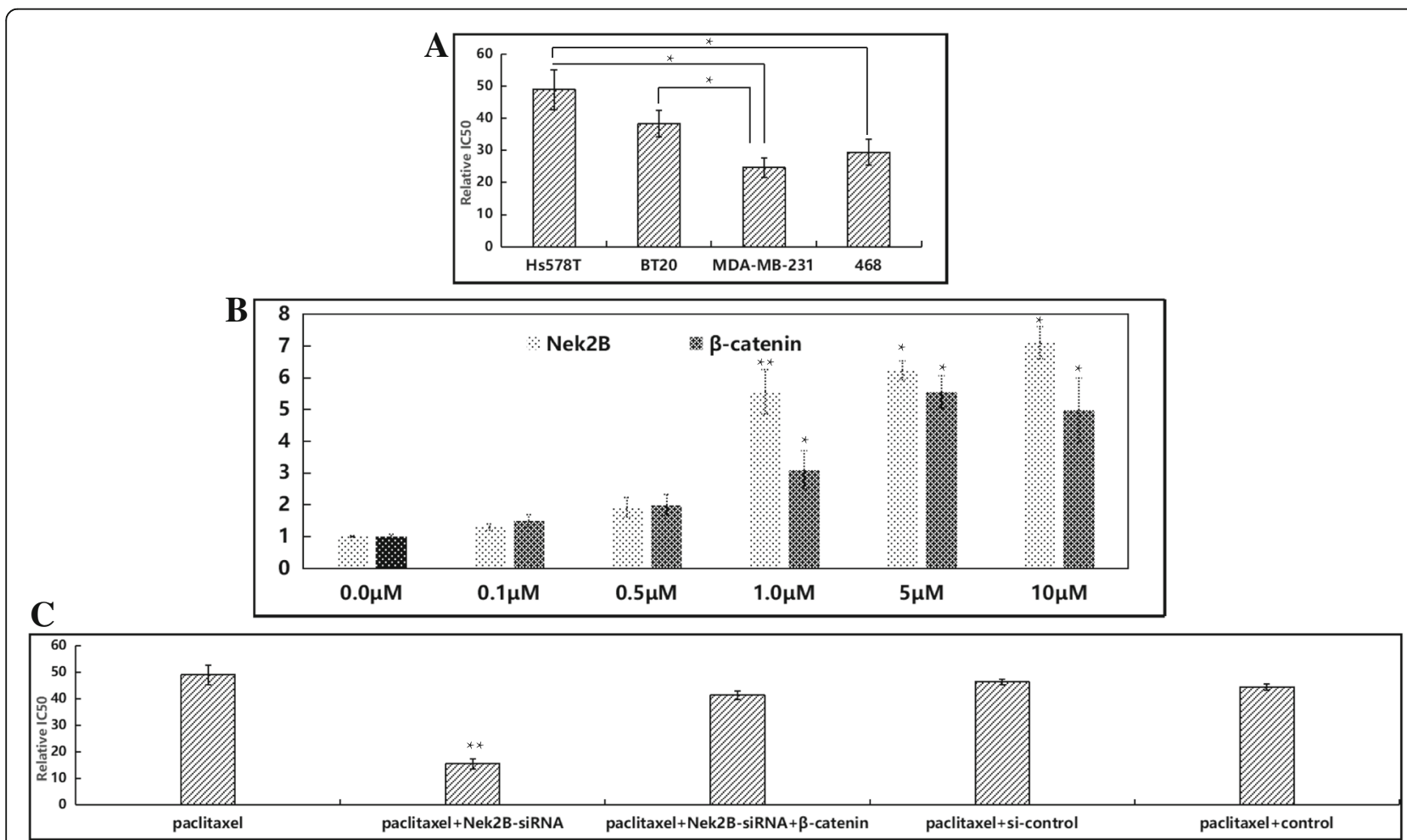

Fig. 4 (a) CCK8 assay was used to detect the IC50 value of TNBC cell lines; (b) The Nek2B and $\beta$-catenin mRNA expression were detected by Q-RT-PCR after chemotherapy-sensitive cells MDA-MB-231 were treated with different concentrations of paclitaxel; (c) Nek2B-siRNA were transfected into drug-resistant cell $\mathrm{Hs} 578 \mathrm{~T}$ to test drug resistance reversal rate of Nek2B and $\beta$-catenin to paclitaxel. ${ }^{*} P<0.05$; ${ }^{* *} P<0.01$ 
received 2-3 cycles of neoadjuvant chemotherapy. $\mathrm{pCR}$ (pathological complete response) was achieved in 1 patient, PR (partial response) was achieved in 14 patients, SD (stable condition) was achieved in 10 patients, and PD (disease progression) was achieved in 18 patients. Therefore, our research group detected the expression of Nek2B mRNA in 42 postoperative cancer tissues. As shown in Table 2, only $26.7 \%$ of patients in the Nek2B positive expression group achieved $\mathrm{PR}$, while up to $53.3 \%$ of patients achieved $\operatorname{PD}(P=0.003)$. It can be seen that patients with positive Nek2B expression developed drug resistance to paclitaxel-containing neoadjuvant chemotherapy.

Human TNBC cell lines Hs578T, BT20, MDA-MB-231 and MDA-MB-468 were treated with paclitaxel at different concentrations for $72 \mathrm{~h}$, and CCK8 was added. OD values were read by a microplate reader. As shown in Fig. 4a, IC50 of Hs578T, BT20, MDA-MB-231 and 468 cell lines were $48.98 \pm 1.68 \mathrm{~mol} / \mathrm{L}, \quad 38.33 \pm 4.16 \mathrm{~mol} / \mathrm{L}$, $24.66 \pm 2.99 \mathrm{~mol} / \mathrm{L}$, and $29.45 \pm 3.95 \mathrm{~mol} / \mathrm{L}$, respectively, with statistically significant differences $(P<0.05)$. Thus,
Hs578T and BT20 cell lines were relatively resistant, while MDA-MB-231 and 468 cell lines were relatively sensitive. Further induction in chemotherapy-sensitive cells MDA-MB-231 with different concentrations of paclitaxel $(0 \mathrm{M}, 0.1 \mathrm{M}, 0.5 \mathrm{M}, 1 \mathrm{M}, 5 \mathrm{M}, 10 \mathrm{M})$ showed a concentration-dependent increase in Nek2B and $\beta$-catenin mRNA levels (Fig. 4b). We further transfected Nek2B-siRNA into drug-resistant cell Hs578T, showed that the drug resistance reversal rate of Nek2B to paclitaxel was 3.1 times $(15.621 .89 \mathrm{~mol} / \mathrm{L}$ vs. 49.07 $3.61 \mathrm{~mol} / \mathrm{L}$ ), and with the overexpression of $\beta$-catenin, the IC50 were increased $(P<0.05)$ (Fig. 4c), indicating that Nek2B-siRNA could improve the sensitivity of TNBC cell line to paclitaxel, suggesting the potential role of Nek2B and wnt/ $\beta$-catenin pathways in the progression of drug resistance in TNBC cells.

Nek2B and $\beta$-catenin expression status in TNBC cells We analysied the mRNA and protein expression of Nek2B and $\beta$-catenin by Q-RT-PCR (Fig. 5a) and
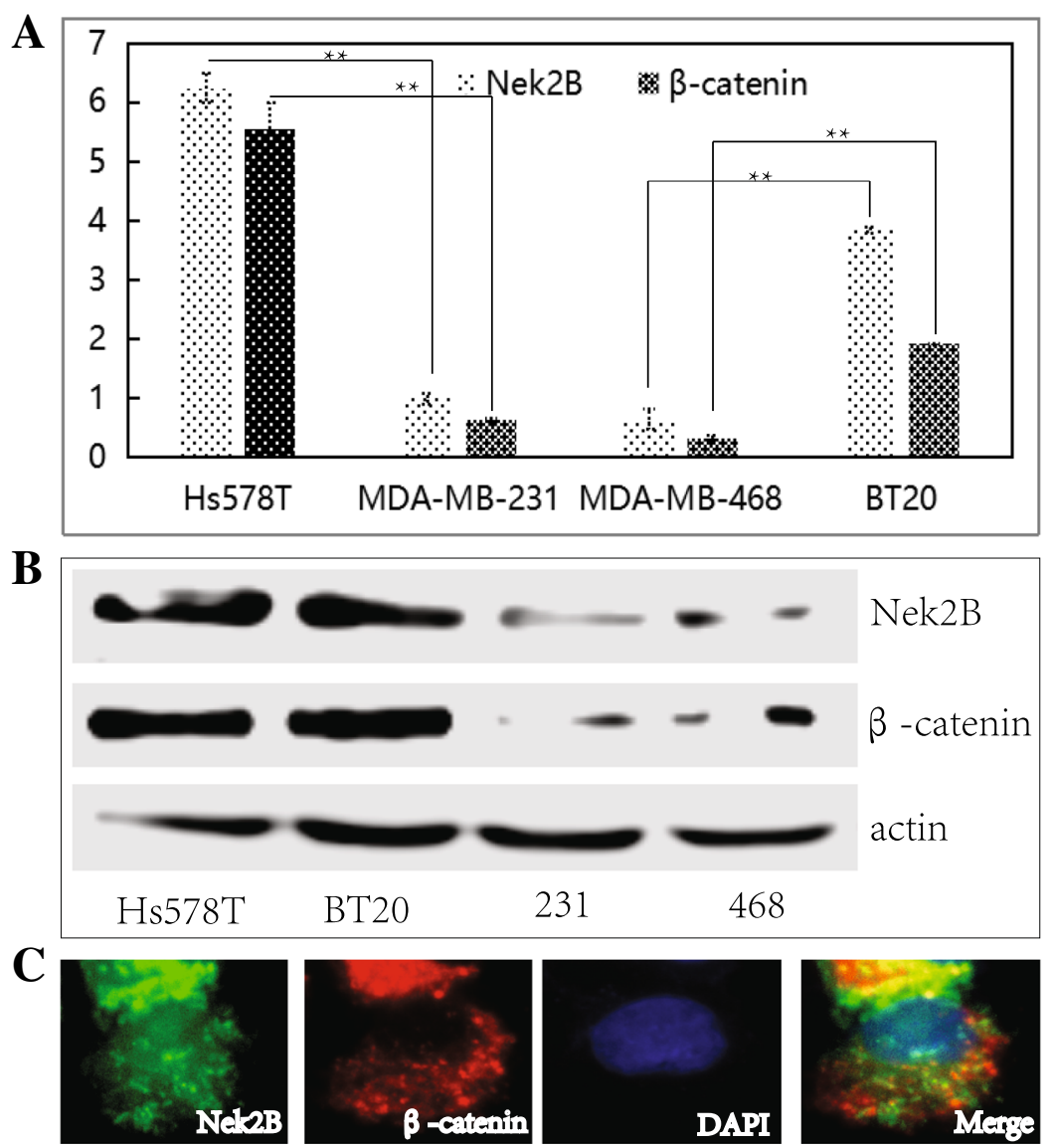

Fig. 5 The mRNA (a) and protein (b) expression of Nek2B and $\beta$-catenin by Q-RT-PCR and Western blot in TNBC cells; Results are represented as mean \pm S.E. c The expression pattern of Nek2B and $\beta$-catenin were showed by color images of immunofluorescence staining in $\mathrm{H}_{5} 578 \mathrm{~T}$ cells. ${ }^{*} P<0.05 ;{ }^{*} P<0.01$ 


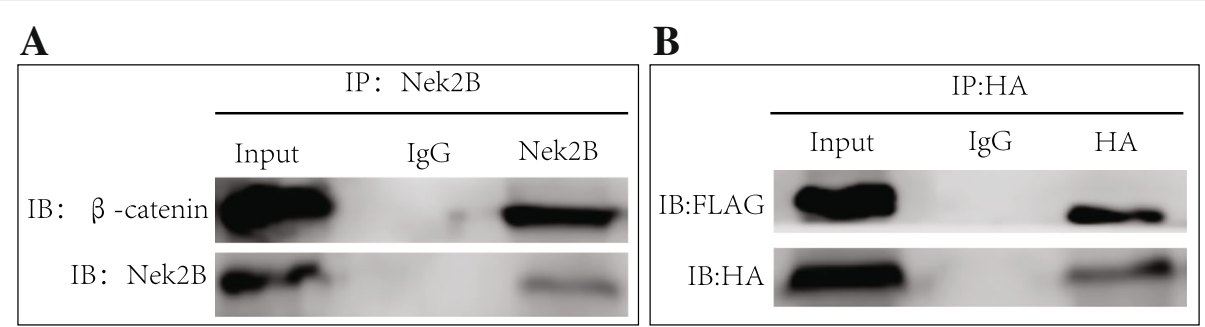

Fig. 6 (a) CO-IP was used to detect the combination of endogenous Nek2B and $\beta$-catenin in Hs578T cells; (b) Hs578T cells were transfected of HA- $\beta$-catenin and FLAG-Nek2B, CO-IP was used to detect the combination of Nek2B and $\beta$-catenin

Western-blot (Fig. 5b) in TNBC cells. It showed that the mRNA and protein expression level of Nek2B and $\beta$-catenin were higher in Hs578T and BT20 cells than in the MDA-MB-231 and MDA-MB-468 cells; Immunofluorescence double staining showed that Nek2B was located in the nucleus and cytoplasm, and $\beta$-catenin was mainly located in the cell membrane and cytoplasm (Fig. 5c). These results confirmed our preliminary hypothesis that there was a positive correlation between the expressions of $\mathrm{Nek} 2 \mathrm{~B}$ and $\beta$-catenin in TNBC cells.

\section{The targeted combination of Nek2B with $\beta$-catenin} Immune protein coprecipitation (CO-IP) experiment showed that endogenous Nek2B and endogenous $\beta$-catenin exists in the form of compounds in Hs578T cells (Fig. 6a). At the same time, Hs578T cells were transfected with $\beta$-catenin of HA tag and Nek2B FLAG tag. FLAG-tag was used to precipitate Nek2B protein antibody, and Western blot showed the existence of $\beta$-catenin in the protein complexes (Fig. 6b). This further confirms that Nek2B can combine with $\beta$-catenin.

We want to test whether the complex formed by Nek2B and $\beta$-catenin participate in the $\beta$-catenin phosphorylation and degradation using $\mathrm{CO}-\mathrm{IP}$ in Hs578T cell. Nek2B antibody is used to immunoprecipitate $\beta$-catenin, TCF4, Axin 1 and GSK3 $\beta$ protein. As shown in Fig. 7a, Nek2B can be combined with $\beta$-catenin and TCF4, but not with Axin 1 and GSK3 $\beta$. Cytoplasm and nucleus of Hs578 cell line were detected by nucleoplasmic separation assay and CO-IP, it showed that Nek2B, $\beta$-catenin and TCF4 can form complex in the nucleus (Fig. 7b). This suggests that the Nek2B and $\beta$-catenin complex directly enters the nucleus and forms a transcription complex with TCF4.

\section{Regulation of $\beta$-catenin by Nek2B in TNBC cell lines}

Nek2B-siRNA and Nek2B overexpression plasmids were transfected into Nek2B high expression cells and low expression cells, respectively. Data showed that the expression levels of both Nek2B and $\beta$-catenin mRNA were reduced in Hs578T(Fig. 8a) and BT20 cells (Fig. 8b) after Nek2B was interfered. Decreased expression of phosphorylated $\beta$-catenin $(\mathrm{p}-\beta$-catenin) protein was found in Hs578T cells (Fig. 8c). The expression levels of both Nek2B and $\beta$-catenin mRNA were elevated in MDA-MB-231 (Fig. 8d) and MDA-MB-468 cells (Fig. 8e) after Nek2B was overexpressed. Increased

\begin{tabular}{|c|c|c|c|c|c|c|c|c|c|c|}
\hline \multicolumn{4}{|l|}{ A } & \multicolumn{7}{|l|}{$\mathbf{B}$} \\
\hline & \multicolumn{3}{|c|}{ IP: Nek2B } & \multirow{2}{*}{ IP:Nek2B } & \multicolumn{3}{|c|}{ Cytoplasm } & \multicolumn{3}{|c|}{ Nulei } \\
\hline & Input & $\operatorname{IgG}$ & Nek2B & & Input & $\operatorname{IgG}$ & Nek2B & Input & $\operatorname{IgG}$ & Nek2B \\
\hline IB: $\beta$-catenin & - & &. & IB:TCF-4 & 0 & & & & & 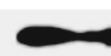 \\
\hline IB:TCF-4 & a & & - & IB: $\beta$-catenin & & & & & & - \\
\hline IB:Axin 1 & $\ldots$ & & & IB: $\alpha$-tubulin & & & & & & \\
\hline IB:GSK3 $\beta$ & $\because$ & & & IB:Laminb1 & & & & & & \\
\hline
\end{tabular}

Fig. 7 (a) CO-IP was used to detect whether Nek2B/ $\beta$-catenin complex participate in the $\beta$-catenin phosphorylation and degradation in Hs578T cell; (b) Cytoplasm and nucleus of Hs578 cell line were detected by nucleoplasmic separation assay and CO-IP 
expression of phosphorylated $\beta$-catenin ( $\mathrm{p}-\beta$-catenin) protein was found in MDA-MB-231 cells (Fig. 8f). Nucleoplasmic separation technique showed that after Nek2B was interfered in Hs578T cell line, the expression level of $\beta$-catenin in the nucleus decreased, but not in cytoplasm (Fig. 8g). When Nek2B was overexpressd in MDA-MB-231 cell line, the expression level of $\beta$-catenin in the nucleus increased, but not in cytoplasm (Fig. $8 \mathrm{~h}$ ). This indicates that Nek2B mainly regulates the expression of $\beta$-catenin in TNBC nucleus.

Immmunofluorescence results showed that the nuclear penetration of $\beta$-catenin was weakened or even disappeared after Nek2B was interfered in Hs578T and BT20 cells (Fig. 9a), while the ability of nuclear penetration was obvious enhanced after Nek2B was overexpressed in MDA-MB-231 and 468 cells (Fig. 9b).

\section{The binding of Nek2B, $\beta$-catenin and LEF-1}

To detect whether the Nek2B, $\beta$-catenin and TCF4 complex can bind to the LEF-l promoter region, we detected the binding ability of the complex with LEF-1 promoter in Hs578Tcell lines by chromosomal immunoprecipitation. The relationship between Nek2B and LEF-1 promoter is shown in Fig. 10. It is found that Nek2B, $\beta$-catenin and TCF4 can be binded with the WRE functional area of LEF-1 promoter (Fig. 10a), while they can't

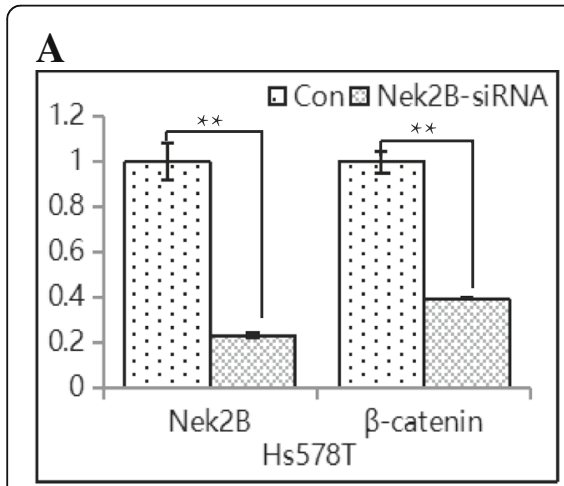

\section{D}

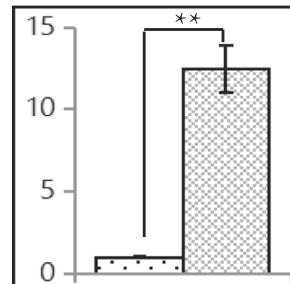

Nek2B
B

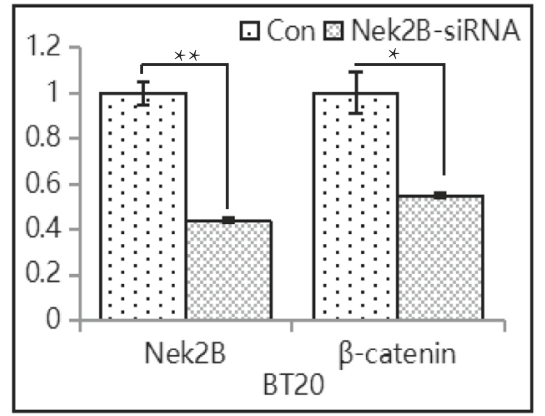

$\mathbf{E}$

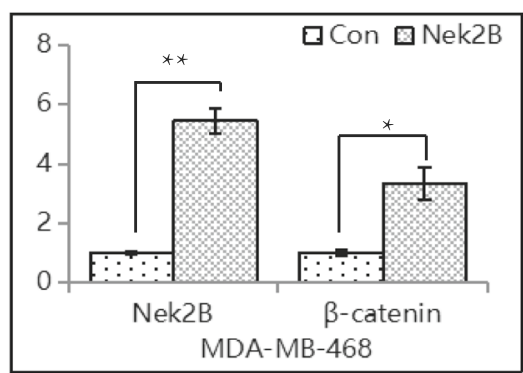

C

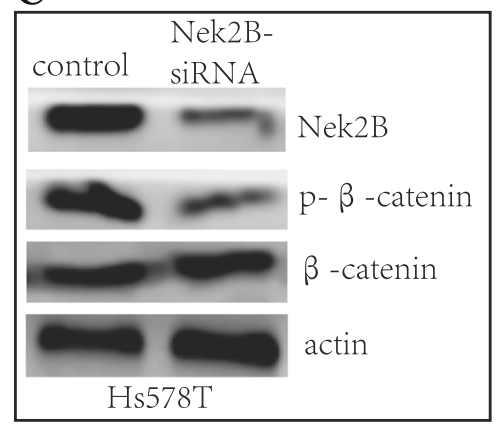

F

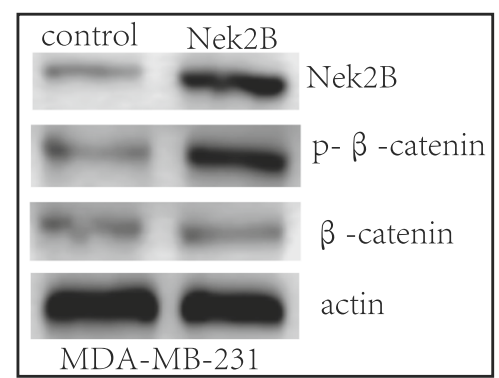

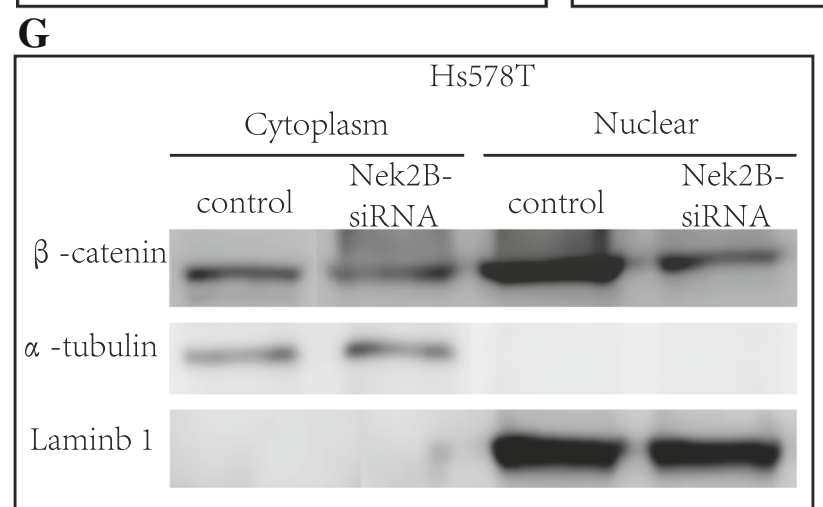

$\mathbf{H}$

MDA-MB-231

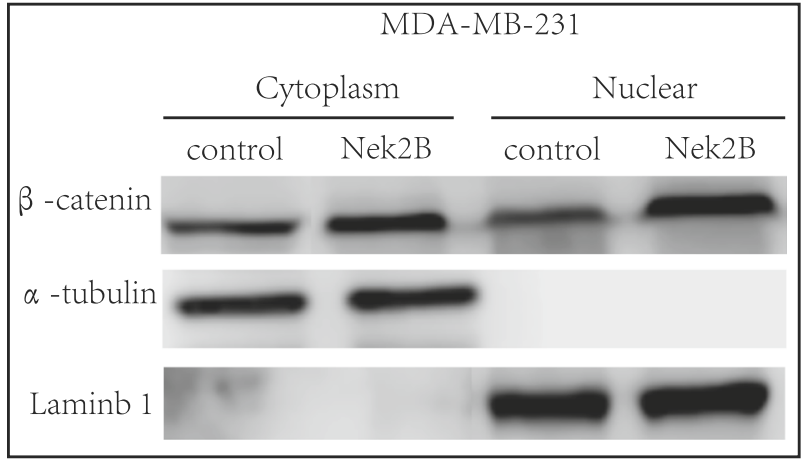

Fig. $8 \mathrm{Hs} 578 \mathrm{~T}$ (a) and BT20 (b) cells were transfected with Nek2B siRNA, Nek2B and $\beta$-catenin mRNA levels were analyzed by qRT-PCR; (c) Western blot analysis was used to detect the Nek2B and p- $\beta$-catenin protein expression in Hs578T cells after transfected with Nek2B siRNA. Actin is shown as loading control; MDA-MB-231(d) and MDA-MB-468 (e) cells were transfected with Nek2B plasmid, Nek2B and $\beta$-catenin mRNA levels were analyzed by qRT-PCR; (f) Western blot analysis was used to detect the Nek2B and p- $\beta$-catenin protein expression in MDA-MB-231 cells after transfected with Nek2B plasmid; Nucleoplasmic separation technique was used to detect the expression of $\beta$-catenin in nucleus and cytoplasm after Hs578T cells were transfected with Nek2B siRNA (g) and MDA-MB-231 cells were transfected with Nek2B plasmid (h). ${ }^{*} P<0.05 ;{ }^{* *} P<0.01$ 
locate in the LEF-1 open reading framework (ORE) (Fig. 10b). To examine whether Nek2B affects the activity of LEF-1 promoter, Nek2B-siRNA or Nek2B plasmid were cotransfected with a luciferase reporter driven by the full-length promoter of the LEF-1 gene into Hs578T cells or MDA-MB-231 cells, respectively, and luciferase assays were performed. Down-regulation of Nek2B expression by Nek2B-siRNA decreased (Fig. 10c), whereas overexpression of Nek2B increased, the activation of the LEF-1 promoter (Fig. 10d). Down-regulation of $\beta$-catenin by $\beta$-catenin shRNA reduced LEF-1 promoter activity (Fig. 10e), whereas overexpression of $\beta$-catenin enhanced LEF-1 promoter activity (Fig. 10f). We next cotransfected Nek2B with $\beta$-catenin shRNA in MDA-MB-231 cells expressing a luciferase reporter driven by the full-length LEF-1 promoter. The results showed that Nek2B increased LEF-1 promoter activity, which was reversed by suppression of $\beta$-catenin (Fig. 10g). ChIP assays showed the combination of $\beta$-catenin and LEF-1 promoter disappears with the silence of Nek2B(Fig. 10h), similarly, after the interference of $\beta$-catenin, the binding of Nek2B to the LEF-1 promoter also disappeared (Fig. 10i). The above results show that Nek2B and $\beta$-catenin depend on each other to aggregate to LEF-1 promoter WRE region.

\section{Nek2B activates the wnt pathway}

We previously found that Nek2B was closely related to the wnt signaling pathway using bioinformatics. Nek2B-siRNA or Nek2B plasmid were transfected to the Hs578T and BT20 or MDA-MB-231 and 468 cell lines, respectively. Down-regulation of Nek2B expression by Nek2B-siRNA decreased (Fig. 11a), whereas overexpression of Nek2B increased the activity of TOP/FOP (Fig. 11b). These results further confirm that Nek2B can activate wnt signaling pathway. To detect whether Nek2B affects the expression of downstream target genes of wnt pathway, PCR and westem blot assay were used to detect the expression of c-myc, cyclinDl and Axin2 of Hs578T and MDA-MB-231 cell lines. After interfering with Nek2B in $\mathrm{Hs} 578 \mathrm{~T}$ cell lines, the expression of c-myc, cyclinDl and Axin2 were decreased significantly (Fig. 11c). It was found that the expression of c-myc, cyclinDl and Axin2 were upregulated with the overexpression of Nek2B(Fig. 11d), indicating that Nek2B not only combines with $\beta$-catenin

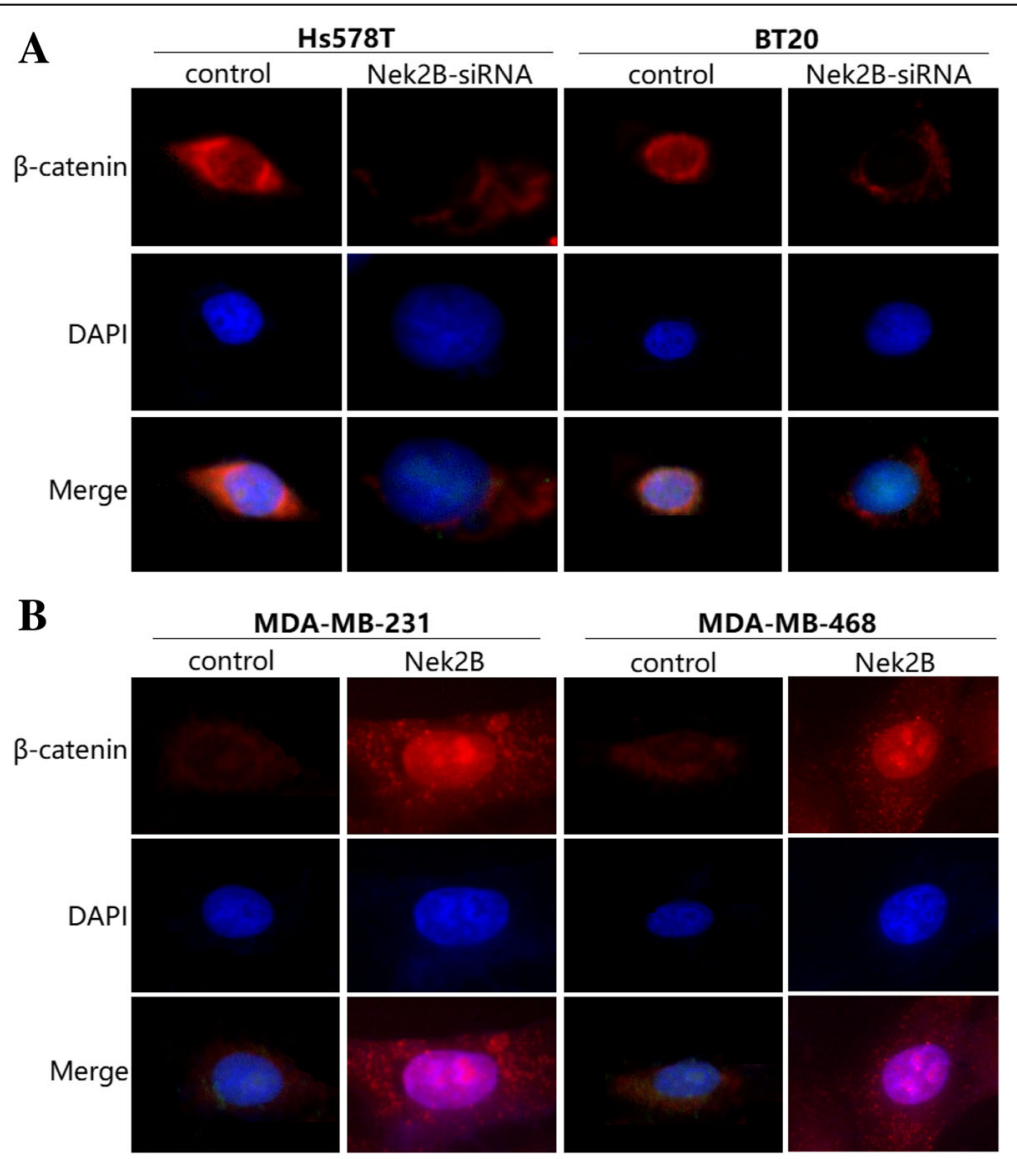

Fig. 9 Immmunofluorescence was used to show the $\beta$-catenin expression after Hs578T cells and BT20 cells were transfected with Nek2B siRNA (a) and MDA-MB-231 cells and 468 cells were transfected with Nek2B plasmid (b) 
A

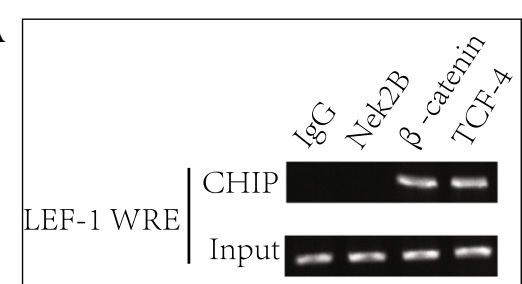

C

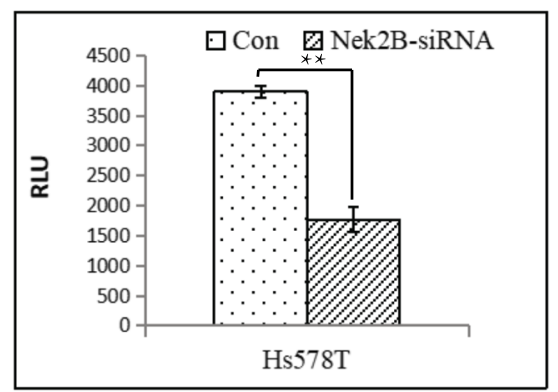

$\mathbf{E}$
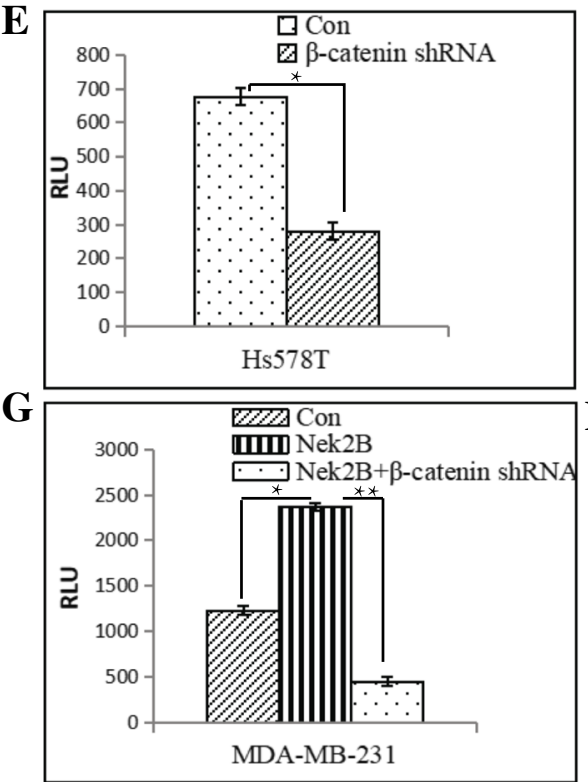

B

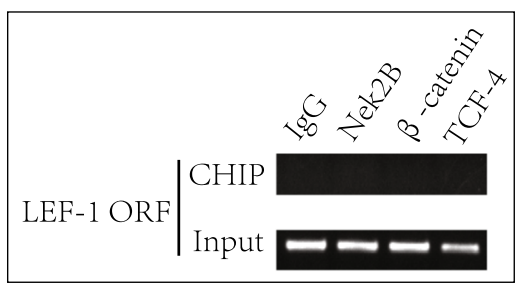

D

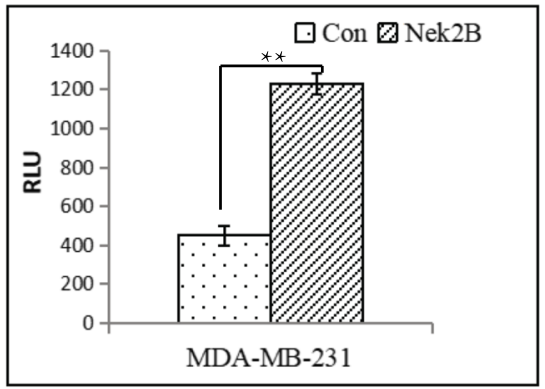

$\mathbf{F}$
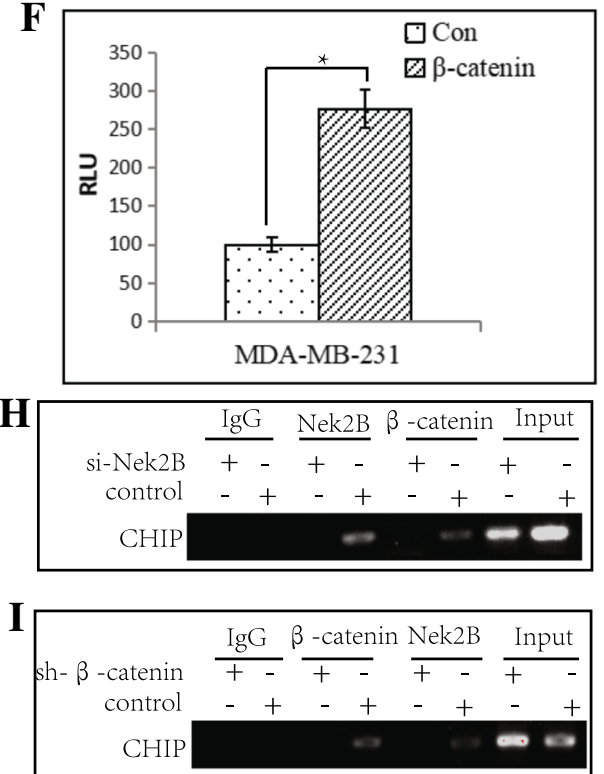

Fig. 10 The relationship between Nek2B and LEF-I WRE (a) and LEF-I ORF (b) promoter was analysed using CHIP; (c)Hs578T cells were cotransfected with control or Nek2B-siRNA along with the pGL4-LEF-1-Prom-Luc reporter. Data points represent the mean \pm S.D. of triplicate samples from two independent experiments. RLU: Relative Luciferase Units; (d) MDA-MB-231 cells were cotransfected with control or Nek2B along with the pGL4-LEF-1-Prom-Luc reporter; (e)Hs578T cells were cotransfected with control or $\beta$-catenin-shRNA along with the pGL4-LEF-1Prom-Luc reporter; (f)MDA-MB-231 cells were cotransfected with control or $\beta$-catenin along with the pGL4-LEF-1-Prom-Luc reporter; (g) MDA-MB231 cells were transfected with Nek2B alone or Nek2B and $\beta$-catenin shRNA together along with the pGL4-LEF-1-prom-Luc reporter. Repression of $\beta$-catenin could overcome the promotion of LEF-1 promoter activity by Nek2B; ChIP assays was used to detect the combination of $\beta$-catenin and LEF-1 promoter with the silence of Nek2B (h), and detect the binding of Nek2B to the LEF-1 promoter with the silence of $\beta$-catenin (i). ${ }^{*} P<0.05 ;{ }^{*} P<0.01$

and TCF4 to form complex, and bind to LEF-1 promoter, but also regulates the expression of wnt downstream target genes.

Nek2B activates the wnt pathway by stabilizing $\beta$-catenin To determine the association between Nek2B activates wnt signaling pathway and $\beta$-catenin, control, Nek2B, Nek2B + sh-control or Nek2B + sh- $\beta$-catenin plasmids were transfected into MDA-MB-231 cell lines, the expression levels of TOP/FOP reporting system (Fig. 12a) and the downstream target genes c-myc, cyclinDl and Axin2 of wnt signaling pathway were detected respectively (Fig. 12b). It was found that after overexpression of Nek2B, the activity of wnt signaling pathway increased, and with the knockout of $\beta$-catenin, not only the activity of wnt signaling pathway was significantly 

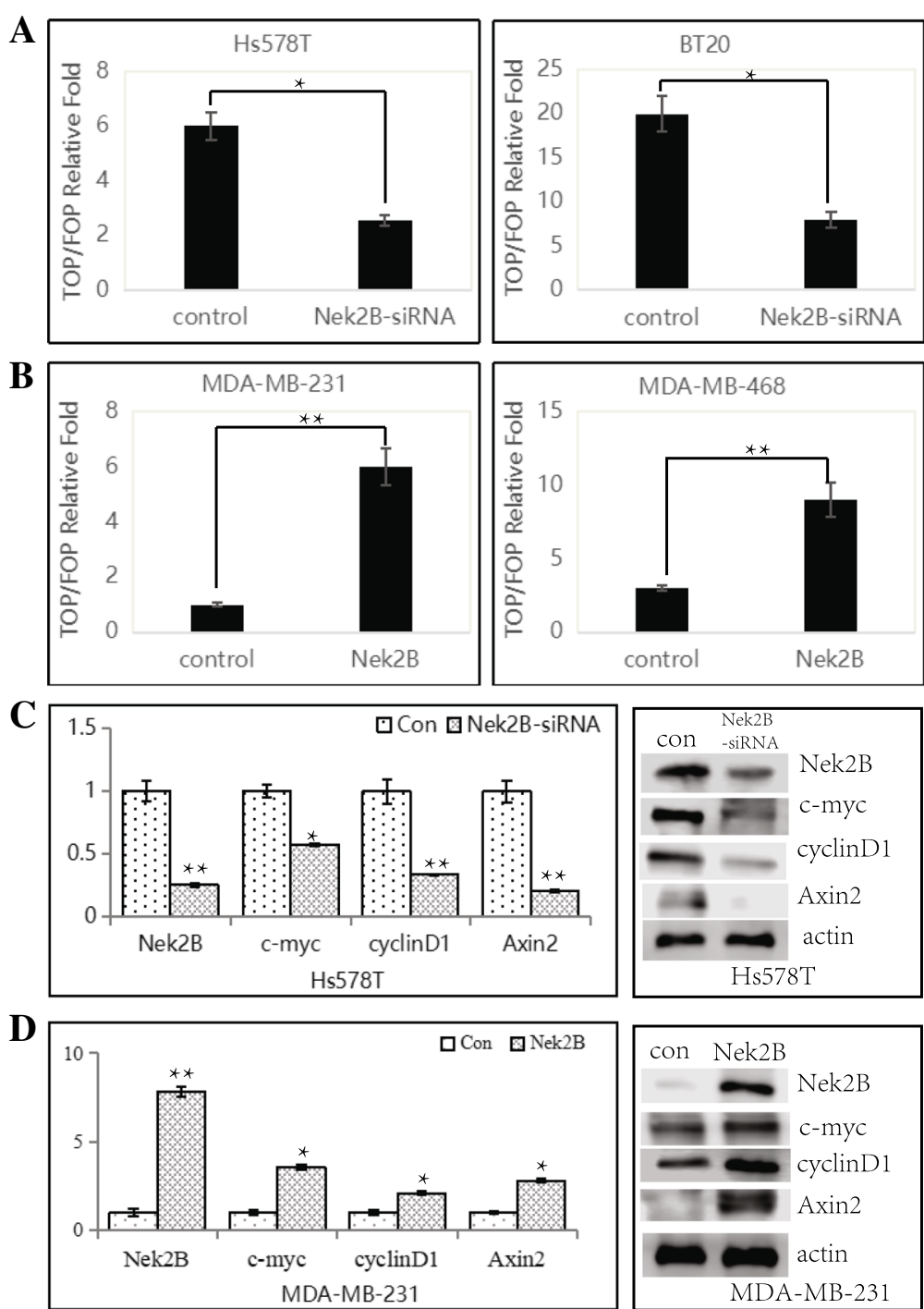

Fig. 11 The activity of TOP/FOP was detected after Nek2B-siRNA or Nek2B plasmid were transfected to the cell lines Hs578T and BT20 (a) or MDA-MB-231 and 468 (b), respectively; PCR and westem blot assay were used to detect the expression of downstream target genes of wnt pathway after Nek2B-siRNA was transfected to Hs578T cells (c) and Nek2B plasmid were transfected to MDA-MB-231 cell (d). ${ }^{*} P<0.05 ;{ }^{*} P<0.01$

down-regulated, but also the protein expression levels of c-myc, cyclinDl and Axin2 were decreased. Then we used transwell cell invasion experiment to verify the changes in the invasion ability of MDA-MB-231 cell line after transfection of control, Nek2B, Nek2B + sh-control or Nek2B + sh- $\beta$-catenin plasmids (Fig. 12c). It was found that the invasion ability of MDA-MB-231 cell line was significantly increased after overexpression of Nek2B, while decreased with the knockout of $\beta$-catenin. The statistical results of the invasion experiment clearly suggest that Nek2B and $\beta$-catenin co-promote tumor cell invasion and metastasis.

\section{Combination treatment using Nek2B siRNA and paclitaxel} in nude mice

To further detect the effect of Nek2B and $\beta$-catenin in TNBC chemotherapy resiatance, we performed a combination treatment using Nek2B siRNA and paclitaxel which disrupted the therapeutic targets of spindle poisons in nude mouse model. As shown in Fig. 13a, the tumor volume in Nek2B siRNA combining with paclitaxel group was decreased compared with Nek2B siRNA group $(P<0.01)$ and paclitaxel group $(P<0.05)$, respectively. With the overexpression of $\beta$-catenin, the tumor volume were increased. The data demonstrated that 


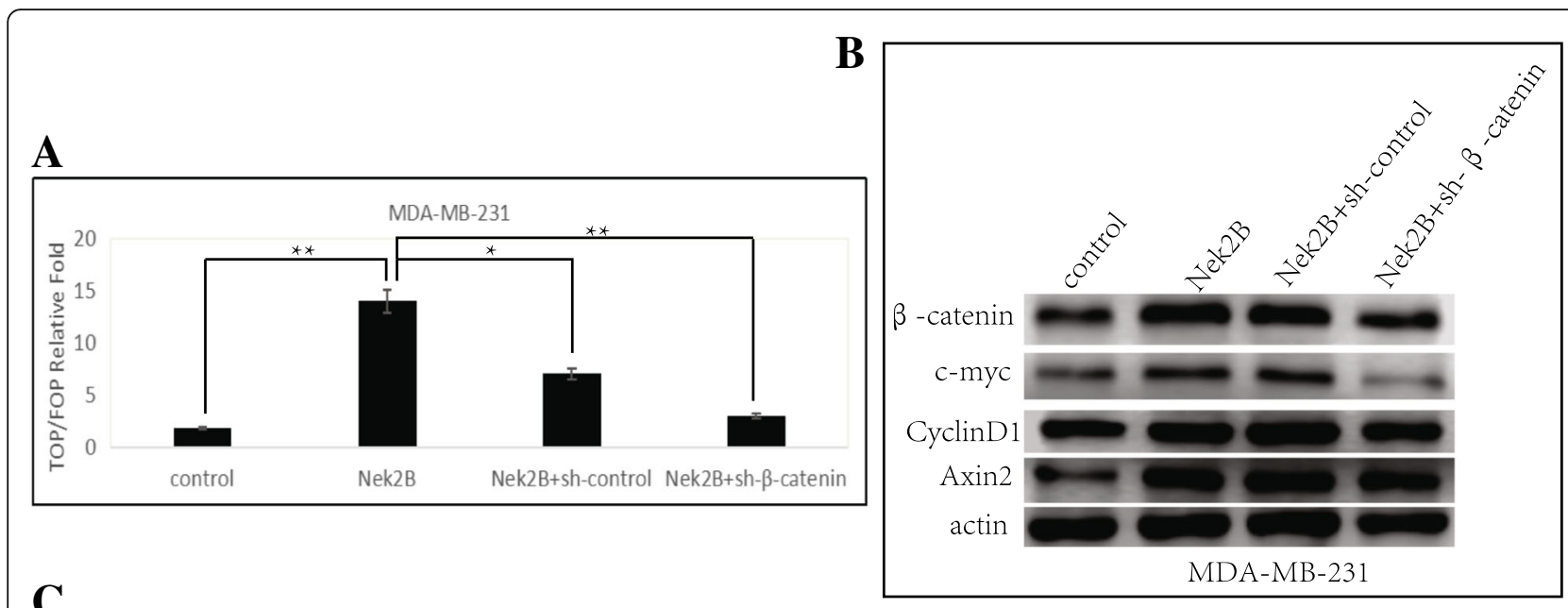

C

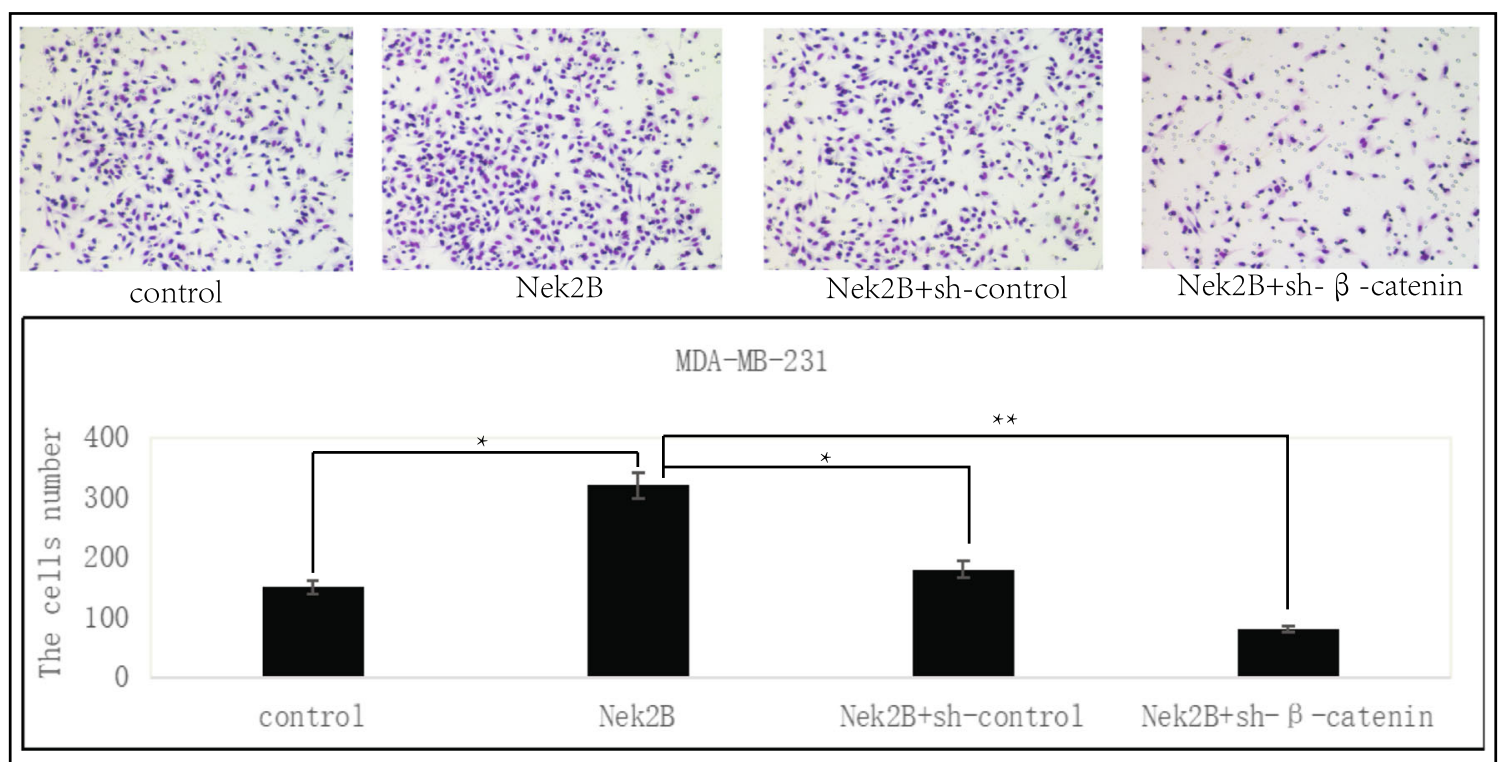

Fig. 12 Nek2B activates the wnt pathway by stabilizing $\beta$-catenin. Control, Nek2B, Nek2B + sh-control or Nek2B+ sh- $\beta$-catenin plasmids were transfected into MDA-MB-231 cell lines, and the expression levels of TOP/FOP reporting system (a) and the downstream target genes c-myc, cyclinDI and Axin2 of wnt signaling pathway were detected (b) respectively;(c) Transwell cell invasion experiment was used to verify the changes in the invasion ability of MDA-MB-231 cell line after transfection of control, Nek2B, Nek2B + sh-control or Nek2B + sh- $\beta$-catenin plasmids. ${ }^{*} P<0.05 ;{ }^{*} P<0.01$

combination treatment using Nek2B siRNA and paclitaxel may suppress TNBC tumor growth rate more efficiently than paclitaxel alone or Nek2B siRNA alone, indicating the potential role of Nek2B and wnt/ $\beta$-catenin pathways in the progression of drug resistance. Total RNA extracts from the tumors were examined for expression levels of Nek2B, $\beta$-catenin and downstream target genes(c-myc, cyclinD1, Axin2) of wnt pathway. The results indicated that Nek2B can regulate the expression of $\beta$-catenin and wnt downstream target genes in vivo (Fig. 13b, c).

\section{Discussion}

Nek2B plays an established role in centrosome separation, and a number of centrosomal substrates have been identified $[17,18]$. Nek2B has also been shown to negatively regulate primary cilia assembly, since ablation of the kinase led to an increase in cilia assembly and a delay in disassembly [19]. Despite these observations, mechanistic insights and substrates were lacking. Here we identify Nek2B and $\beta$-catenin were co-expressed in TNBC and correlated with the patients prognosis, and $\beta$-catenin may be a major substrate of Nek2B. To our knowledge, this is the first report demonstrating the role of Nek2B and $\beta$-catenin co-expression status in TNBC.

Chemotherapy remains the mainstay for the treatment of TNBC due to lack of targeted therapies [20]. However, despite initial chemosensitivity, metastatic relapse paradoxically appears to occur at higher rates 


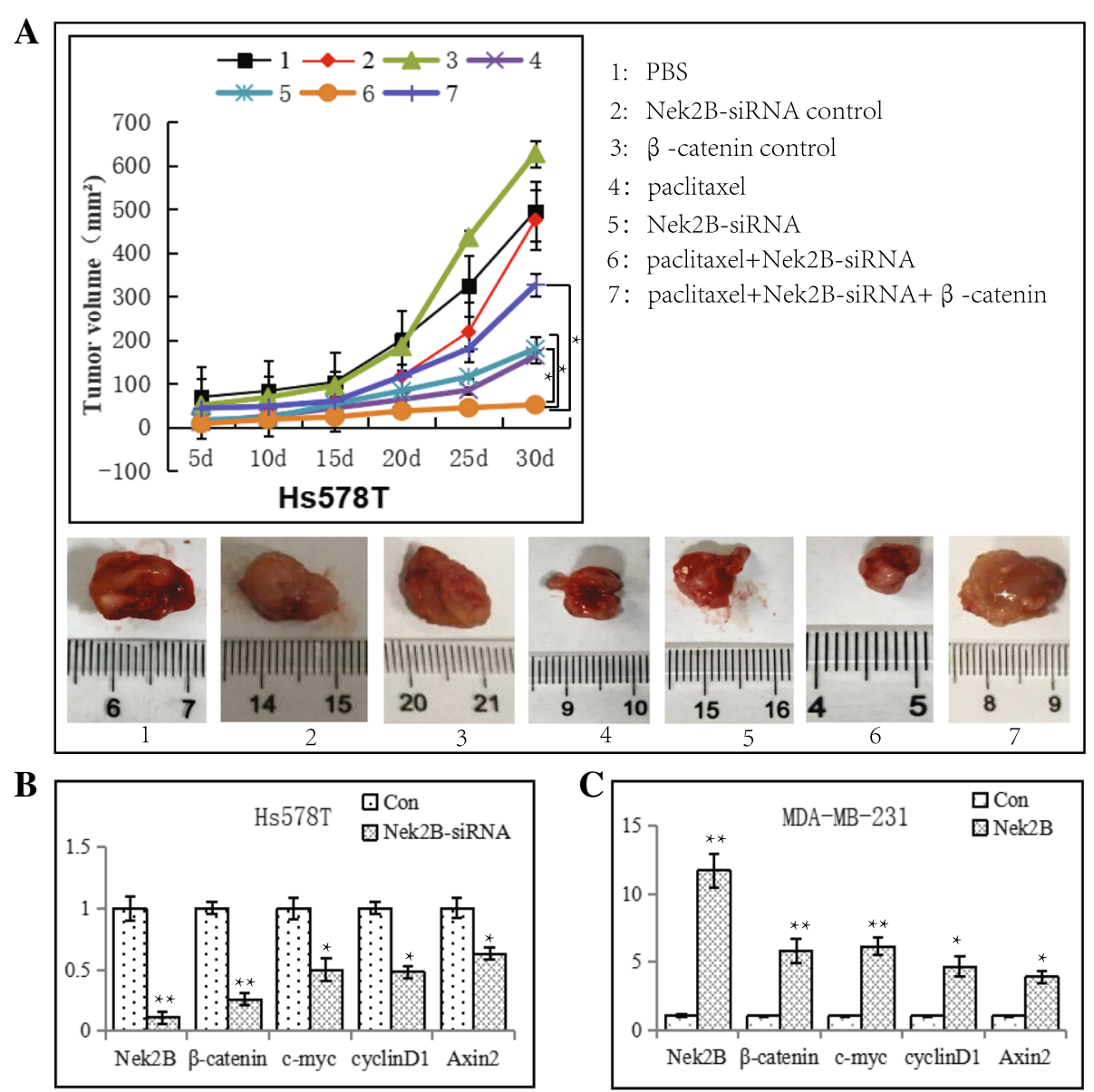

Fig. 13 In vivo experiments (a) The nude mice were divided into five groups (1-7) by different treatment, 1: PBS, 2: Nek2B-siRNA control, 3: $\beta$-catenin control, 4:paclitaxel, 5: Nek2B siRNA, 6: Nek2B siRNA combining with paclitaxel, 7: Nek2B siRNA and paclitaxel combining with $\beta$-catenin. Total RNA extracts from the tumors which were transfacted with Nek2B-siRNA in Hs578T cells (b) and Nek2B plasmid in MDA-MB-231 cells (c) were examined for expression levels of Nek2B, $\beta$-catenin and downstream target genes. ${ }^{*} P<0.05$; ${ }^{*} P<0.01$

for TNBC [21]. In the present study, patients with positive Nek2B expression developed drug resistance to paclitaxel-containing neoadjuvant chemotherapy. We also found chemothearpy-resistant TNBC cells showed higher expression of Nek2B and $\beta$-catenin. This is consistent with Misra et al. [22] and TIEN et al. [23] findings, they put forward that Nek2 stimulates the expression of $\mathrm{ABC}$ transporters by activation of AKT and its downstream targets PIM1 and NF-kB, resulting in drug resistance of cancer cells. We also found that Nek2B-siRNA could improve the sensitivity of TNBC cell line to paclitaxel, and $\beta$-catenin can increase drug resistance rate of Nek2B-siRNA to paclitaxel, suggesting the potential role of Nek2B and wnt $/ \beta$-catenin pathways in the development and progression of drug resistance in TNBC cells. Although it has been previously shown that Nek2 depletion affected the kinetochores-microtubule attachment, inducing a spindle checkpoint imbalance and abnormal clustering of kinetochore components, resulting in increased sensitivity of cells to the microtubule targeting anticancer drug paclitaxel [8] in contrast, Spallarossa et al. [24] described that the increase in cell sensitivity of Nek2-depleted TNBC cells in combination with doxorubicin may be due to the down-regulation of TRF1 and the checkpoint kinase, Chk2, inducing chromosomal abnormalities and altering the cell cycle. Knockdown of $\beta$-catenin in TNBC cells significantly decreased cell migration and made TNBC cells more sensitive to chemotherapeutic drugs like cisplatin and doxorubicin [25]. Zhou et al. [26] pointed that knock-down of $\beta$-catenin abrogates Nek2-induced colony formation and drug resistance indicating that $\beta$-catenin plays indeed an important role in Nek2 function. Our study showed that the patient group with positive co-expression pattern of Nek2B and $\beta$-catenin had the worst DFS in TNBC patients, and Nek2B and $\beta$-catenin co-promote tumor cell invasion 
and metastasis. The association of Nek2B or $\beta$-catenin with Ki67 suggests that the decreased outcomes are related to increased proliferation in these tumours.

As the literatures reported by Zhang et al. [27] and Seung et al. [28], our study showed that Nek2B can combine with $\beta$-catenin and directly enters the nucleus and forms a transcription complex with TCF4, and Nek2B mainly regulates the expression of $\beta$-catenin in TNBC nucleus. Wnt signaling plays a key role in many tissues and has been implicated in several cancers. Activation of wnt signaling induces cancer cell survival and drug resistance [29]. When cytoplasmic $\beta$-catenin is stabilized, it translocates into the nucleus, where it interacts with a family of T-cell factor/lymphocyte enhancer factor (TCF/LEF) transcription factors to drive cell proliferation by direct induction of cell cycle regulators, such as c-Myc and cyclin D1 [29]. The TCF/LEF transcription factors appear to be the major nuclear targets of $\beta$-catenin. The TCF/ $\beta$-catenin complex also regulates participating in drug resistance [30]. By chromosome immunoprecipitation (CHIP) assay, we found that Nek2B and $\beta$-catenin can co-locate on the TCF/LEFl promoter WRE sequence. And when Nek2B is knocked out, the combination of $\beta$-catenin with the TCF4/LEF-l promoter also disappears. Correspondingly,the binding of Nek2B with TCF4/LEF-1 also disappears with the knockout of $\beta$-catenin. These phenomena suggest that Nek2B can not only promote $\beta$-catenin aggregates into the nucleus, but also mediate the formation of Nek2B-catenin-TCF/LEF transcriptional compound. Nek2B can not only increase the activity of wnt signaling pathway, but also regulate the expression of wnt downstream target genes. Significantly, recent studies also support important roles of both Nek2B and canonical wnt $/ \beta$-catenin signaling in breast cancer $[18,31]$. Based on these findings, we believe that our study establishes a novel link between Nek2B and wnt pathway activation in TNBC and shows mechanistically that Nek2B positively regulates multiple genes required for wnt signaling. Overall, these findings indicate that wnt synthesis and signaling are driving at least a subset of TNBC, in particular those tumors with high Nek2B levels, and that this subset of TNBC may be responsive to wnt synthesis inhibitors or other wnt pathway antagonists that are now entering the clinic. According to the results, we speculate a new layer of Nek2B-mediated chemotherapy-resistant in TNBC (Fig. 14).

Limitations of the current study's findings must be made. There is no validated approach for the assessment of Nek2B or $\beta$-catenin by immunohistochemistry, and we elected to use methods by Lee et al. [32]. On the other hand, our study was restricted to a solitary center and a multicenter study is needed to confirm our results. However, more study is needed to elucidate their relationship with Nek2 and the implications for cancer development.

\section{Conclusion}

In conclusion, our study showed, for the first time, that Nek2B can bind to $\beta$-catenin and the co-expression correlated with TNBC patients poor prognosis. It appears that Nek2B and $\beta$-catenin might synergize to

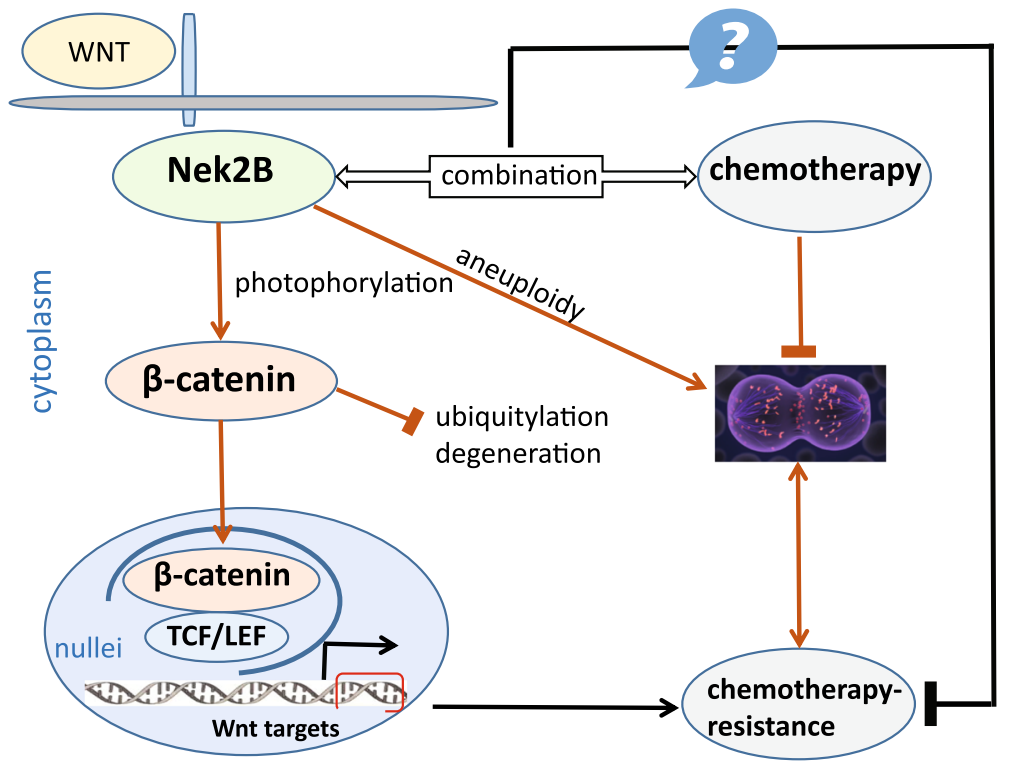

Fig. 14 A hypothesis working model for Nek2B-mediated chemotheropy-resistant mechanism in TNBC. In the classical wnt signaling pathway, the targeted combination of Nek2B and $\beta$-catenin can promote the entry of $\beta$-catenin into the nucleus and activate the transcription factor $\mathrm{TCF} / \mathrm{LEF}$, and then activate the downstream target genes of the wnt pathway and promote drug resistance of TNBC 
promote chemotherapy resistance. Further studies should include TNBC specimens and cells to determine if Nek2 and $\beta$-catenin might synergize to promote chemotherapy resistance.

\section{Abbreviations \\ CHIP: Chromatin immune-precipitation; CO-IP: Co-immunoprecipitation; DFS: Disease-free survival; GEO: Gene Expression Omnibus; OS: Overall survival; pCR: Pathological complete response; PD: Disease progression; PR: Partial response: SD: Stable condition; siRNA: Small interfering RNA: TCF/LEF: T-cell factor/lymphocyte enhancer factor; TNBC: Triple-negative breast cancer}

\section{Acknowledgments}

We are indebted to Dr. Y. Gao and M. Li for their help with pathological section. We thank members of the our laboratory (Dr W. Ma, Z. Wang, Y. Zhang and B.Wang) for engaging discussions and encouragement and Dr. N. Shen for statistical analysis.

\section{Informed consent}

Informed consent was obtained from all individual patients enrolled in the study.

\section{Funding}

This work was funded by Shanxi Science Foundation (201801D221274).

\section{Availability of data and materials}

The authors declare the availability of data and materials.

\section{Authors' contributions}

YW performed, analyzed and interpreted experiments, YJ performed and analyzed experiments; WZ performed the deep sequencing analysis and helped with evaluation; WC provided administrative support and corrected the manuscript draft; SH planned, performed and interpreted experiments and wrote the manuscript. All authors approved the final revised manuscript version.

\section{Ethics approval and consent to participate}

This study was approved by the Second Clinical Medical College, Shanxi Medical University, China and has been performed in accordance with the ethical standards laid down in the 1964 Helsinki declaration and its later amendments.

\section{Consent for publication}

All authors consent for publication.

\section{Competing interests}

The authors declare that they have no competing interests.

\section{Publisher's Note}

Springer Nature remains neutral with regard to jurisdictional claims in published maps and institutional affiliations.

\section{Author details}

'Department of pathology, The Second Clinical Medical College, Shanxi Medical University, 382 Wuyi Road, Taiyuan 030001, People's Republic of China. ${ }^{2}$ Department of general surgery, The Second Clinical Medical College, Shanxi Medical University, 382 Wuyi Road, Taiyuan 030001, People's Republic of China.

Received: 1 April 2019 Accepted: 13 May 2019

Published online: 07 June 2019

\section{References}

1. He $Y$, Jiang $Z$, Chen $C$, Wang $X$. Classification of triple-negative breast cancers based on Immunogenomic profiling. J Exp Clin Cancer Res. 2018;37:327

2. Temian DC, Pop LA, Irimie Al, Berindan-Neagoe I. The epigenetics of triplenegative and basal-like breast Cancer: current knowledge. J Breast Cancer. 2018;21(3):233-43.
3. Su Y, Hopfinger NR, Nguyen TD, Pogash TJ, Santucci-Pereira J, Russo J. Epigenetic reprogramming of epithelial mesenchymal transition in triple negative breast cancercells with DNA methyltransferase and histone deacetylase inhibitors. J Exp Clin Cancer Res. 2018;37:314.

4. Logue SE, McGrath EP, Cleary P, Greene S, Mnich K, Almanza A, Chevet E, Dwyer RM, Oommen A, Legembre P, Godey F, Madden EC, Leuzzi B, Obacz J, Zeng Q, Patterson JB, Jäger R, Gorman AM, Samali A. Inhibition of IRE1 RNase activity modulates the tumor cell secretome and enhances response to chemotherapy. Nat Commun. 2018;9:3267.

5. Uto K, Sagata N. Nek2B, a novel maternal form of Nek2 kinase, is essential for the assembly or maintenance of centrosomes in early Xenopus embryos. EMBO J. 2000;19(8):1816-26

6. Fang $Y$, Zhang $X$. Targeting NEK2 as a promising therapeutic approach for cancer treatment. Cell Cycle. 2016;15(7):895-907.

7. Zeng Y-R, Han Z-D, Wang C, Cai C, Huang Y-Q, Luo H-W, Liu Z-Z, Zhuo Y-J, Dai Q-S, Zhao H-B, Liang Y-X, Zhong W-D. Overexpression of NIMA-related kinase 2 is associated with progression and poor prognosis of prostate cancer. BMC Urol. 2015;15:90

8. Lee J, Gollahon L. Nek2-targeted ASO or siRNA pretreatment enhances anticancer drug sensitivity in triple-negative breast cancer cells. Int J Oncol. 2013:42(3):839-47.

9. Marina M, Saavedra HI. Nek2 and Plk4: prognostic markers, drivers of breast tumorigenesis and drug resistance. Front Biosci (Landmark Ed). 2014;19:352-65.

10. Yang $Y$, Lei $H$, Qiang $Y-W$, Wang B. Ixazomib enhances parathyroid hormone-induced $\beta$-catenin/T-cell factor signaling by dissociating $\beta$ catenin from the parathyroid hormone receptor. Mol Biol Cell. 2017:28(13):1792-803.

11. Lin $Y-Y$, Hsu Y-H, Huang H-Y, Shann Y-J, Huang C-YF, Wei S-C, Chen C-L, Jou T-S. Aberrant nuclear localization of EBP50 promotes colorectal carcinogenesis in xenotransplanted mice by modulating TCF-1 and B-catenin interactions. J Clin Invest. 2012;122(5):1881-94.

12. Su H, Sureda-Gomez M, Rabaneda-Lombarte N, Gelabert M, Xie J, Wu W, Adell T. A C-terminally truncated form of $\beta$-catenin acts as a novel regulator of Wnt/ $\beta$-catenin signaling in planarians. PLoS Genet. 2017:13(10):e1007030

13. Bahmanyar S, Kaplan DD, DeLuca JG, Giddings TH Jr, O'Toole ET, Winey M, Salmon ED, Casey PJ, Nelson WJ, Barth AIM. B-Catenin is a Nek2 substrate involved in centrosome separation. Genes Dev. 2008;22(1):91-105.

14. Mbom BC, Siemers KA, Ostrowski MA, Nelson WJ, Barth AIM. Nek2 phosphorylates and stabilizes $\beta$-catenin at mitotic centrosomes downstream of Plk1. Mol Biol Cell. 2014;25(7):977-91.

15. Shen H, Yang Y, Zhao L, Yuan J, Niu Y. Lin28A and androgen receptor expression in ER-/Her2+ breast cancer. Breast Cancer Res Treat. 2016;156(1):135-47.

16. Wang Y, Shen H, Yin Q, Zhang T, Liu Z, Zhang W, Niu Y. Effect of NIMArelated kinase $2 \mathrm{~B}$ on the sensitivity of breast cancer to paclitaxel in vitro and vivo. Tumour Biol. 2017;39(5):1010428317699754.

17. Wang J, Cheng P, Pavlyukov MS, Yu H, Zhang Z, Kim S-H, Minata M, Mohyeldin A, Xie W, Chen D, Goidts V, Frett B, Hu W, Li H, Shin YJ, Lee Y, Nam D-H, Kornblum HI, Wang M, Nakano I. Targeting NEK2 attenuates glioblastoma growth and radioresistance by destabilizing histone methyltransferase EZH2. J Clin Invest. 2017:127(8):3075-89.

18. Franqui-Machin R, Hao M, Bai H, Gu Z, Zhan X, Habelhah H, Jethava Y, Qiu L, Frech I, Tricot G, Zhan F. Destabilizing NEK2 overcomes resistance to proteasome inhibition in multiple myeloma. J Clin Invest. 2018;128(7):2877-93.

19. Kim S, Lee K, Choi J-H, Ringstad N, Dynlacht BD. Nek2 activation of Kif24 ensures cilium disassembly during the cell cycle. Nat Commun. 2015;6:8087.

20. Sinha A, Agarwal S, Parashar D, Verma A, Saini S, Jagadish N, Ansari AS, Lohiya NK, Suri A. Down regulation of SPAG9 reduces growth and invasive potential of triple-negative breast cancercells: possible implications in targeted therapy. J Exp Clin Cancer Res. 2013;32(1):69.

21. Salaroglio IC, Gazzano E, Abdullrahman A, Mungo E, Castella B, Abdelrahman GEF A-e, Massaia M, Donadelli M, Rubinstein M, Riganti C, Kopecka J. Increasing intratumor C/EBP- $\beta$ LIP and nitric oxide levels overcome resistance to doxorubicin in triple negative breast cancer. J Exp Clin Cancer Res. 2018;37:286.

22. Tien Kuo M, Zesheng L, Yingjie W, Lin-Lee Y, Tatebe S, Mills GB, Unate H. Induction of human MDR1 gene expression by 2-acetylaminofluorene is mediated by effectors of the phosphoinositide 3-kinase pathway that activate NF-kB signaling. Oncogene. 2002;21:1945-54. 
23. Misra S, Ghatak S, Toole BP. Regulation of MDR1 expression and drug resistance by a positive feedback loop involving hyaluronan, phosphoinositide 3-kinase, and ErbB2. J Biol Chem. 2005;280:20310.

24. Spallarossa P, Altieri P, Aloi C, Garibaldi S, Barisione C, Ghigliotti G, Fugazza G, Barsotti A, Brunelli C. Doxorubicin induces senescence or apoptosis in rat neonatal cardiomyocytes by regulating the expression levels of the telomere binding factors 1 and 2. Am J Physiol Heart Circ Physiol. 2009;297:H2169-81.

25. Gangrade A, Pathak V, Augelli-Szafran CE, Wei H-X, Oliver P, Suto M, Buchsbaum DJ. Preferential Inhibition of Wnt/ $\beta$-Catenin Signaling by Novel Benzimidazole Compounds in Triple-Negative Breast Cancer. Int J Mol Sci. 2018;19(5):1524.

26. Zhou W, Yang Y, Xia J, Wang H, Salama ME, Xiong W, Xu H, Shetty S, Chen T, Zeng Z, Shi L, Zangari M, Miles R, Bearss D, Tricot G, Zhan F. NEK2 Induces Drug-resistance Mainly through Activation of Efflux Drug Pumps and Is Associated with Poor Prognosis in Myeloma and Other Cancers. Cancer Cell. 2013;23(1):48-62.

27. Zhang Y, Chidiac R, Delisle C, Gratton J-P. Endothelial NO SynthaseDependent S-Nitrosylation of $\beta$-Catenin Prevents Its Association with TCF4 and Inhibits Proliferation of Endothelial Cells Stimulated by Wnt3a. Mol Cell Biol. 2017;37(12):e00089-17.

28. Shin SH, Lim DY, Reddy K, Malakhova M, Liu F, Wang T, Song M, Chen H, Bae KB, Ryu J, Liu K, Lee M-H, Bode AM, Dong Z. A Small Molecule Inhibitor of the $\beta$-Catenin-TCF4 Interaction Suppresses Colorectal Cancer Growth In Vitro and In Vivo. EBioMedicine. 2017;25:22-31.

29. Gehrke I, Gandhirajan RK, Kreuzer KA. Targeting the WNT/[beta]-catenin/ TCF/LEF1 axis in solid and haematological cancers: multiplicity of therapeutic options. Eur J Cancer. 2009:45:2759-67.

30. Yamada T, Takaoka AS, Naishiro Y, Hayashi R, Maruyama K, Maesawa C, Ochiai A, Hirohashi $\mathrm{S}$. Transactivation of the multidrug resistance 1 gene by T-cell factor $4 / \beta$-catenin complex in early colorectal carcinogenesis. Cancer Res. 2000;60:4761.

31. Neal CP, Fry AM, Moreman C, McGregor A, Garcea G, Berry DP, Manson MM Overexpression of the Nek2 kinase in colorectal cancer correlates with betacatenin relocalization and shortened cancer-specific survival. J Surg Oncol. 2014;110:828-38

32. Lee J, Gollahon L. Mitotic perturbations induced by Nek2 overexpression require interaction with TRF1 in breast cancer cells. Cell Cycle. 2013:12(23):3599-614.

Ready to submit your research? Choose BMC and benefit from:

- fast, convenient online submission

- thorough peer review by experienced researchers in your field

- rapid publication on acceptance

- support for research data, including large and complex data types

- gold Open Access which fosters wider collaboration and increased citations

- maximum visibility for your research: over $100 \mathrm{M}$ website views per year

At $\mathrm{BMC}$, research is always in progress.

Learn more biomedcentral.com/submissions 